\title{
Batch and Continuous Flow Adsorption of Phenolic Compounds from Olive Mill Wastewater: A Comparison between Nonionic and Ion Exchange Resins
}

\author{
Davide Pinelli, ${ }^{1}$ Aurora Esther Molina Bacca, ${ }^{1}$ Ankita Kaushik, ${ }^{1,2}$ Subhankar Basu, ${ }^{2}$ \\ Massimo Nocentini, ${ }^{1}$ Lorenzo Bertin, ${ }^{1}$ and Dario Frascari ${ }^{1}$ \\ ${ }^{1}$ Department of Civil, Chemical, Environmental and Materials Engineering, University of Bologna, Via Terracini 28, \\ 40131 Bologna, Italy \\ ${ }^{2}$ The Energy and Resources Institute (TERI), Darbari Seth Block, IHC Complex, Lodhi Road, New Delhi 110003, India \\ Correspondence should be addressed to Dario Frascari; dario.frascari@unibo.it
}

Received 12 May 2016; Revised 6 July 2016; Accepted 11 July 2016

Academic Editor: Evangelos Tsotsas

Copyright (C) 2016 Davide Pinelli et al. This is an open access article distributed under the Creative Commons Attribution License, which permits unrestricted use, distribution, and reproduction in any medium, provided the original work is properly cited.

\begin{abstract}
The goals of this work were (i) to compare two anion ion exchange resins (IRA958 Cl and IRA67) and a nonionic resin (XAD16) in terms of phenolic compounds adsorption capacity from olive mill wastewater and (ii) to compare the adsorption capacity of the best resin on columns of different length. The ion exchange resins performed worse than nonionic XAD16 in terms of resin utilization efficiency ( $20 \%$ versus $43 \%$ ) and phenolic compounds/COD enrichment factor (1.0 versus 2.5). The addition of volatile fatty acids did not hinder phenolic compounds adsorption on either resin, suggesting a noncompetitive adsorption mechanism. A $\mathrm{pH}$ increase from 4.9 to $7.2 \mathrm{did}$ not affect the result of this comparison. For the best performing resin (XAD16), an increase in column length from 0.5 to $1.8 \mathrm{~m}$ determined an increase in resin utilization efficiency (from $12 \%$ to $43 \%$ ), resin productivity (from 3.4 to $7.6 \mathrm{~g}_{\text {sorbed phenolics }} / \mathrm{kg}_{\text {resin }}$ ), and phenolics/COD enrichment factor (from 1.2 to 2.5). An axial dispersion model with nonequilibrium adsorption accurately interpreted the phenolic compounds and COD experimental curves.
\end{abstract}

\section{Introduction}

Olive mill wastewaters (OMWs) represent a major environmental concern. Indeed, their high COD content (20$200 \mathrm{~g} / \mathrm{L}$ ) and relevant phenolic compounds (PCs) content $(0.1-18 \mathrm{~g} / \mathrm{L})$ result in toxicity, bad smell, and inhibition of seed germination and plant growth [1-5]. Furthermore, the presence of high concentrations of PCs can inhibit aerobic and anaerobic biological processes that could be applied to make OMW suitable for irrigation [6]. On the other hand, several studies showed that OMW PCs have strong antioxidant, antiinflammatory, and antimicrobial properties [1,3,7-11]. OMW contains about $95 \%$ of the PC content of the original olives, as a result of the high solubility of PCs in water $[1,12]$. Several processes were proposed to remove or recover PCs from OMW: solvent extraction with acidic ethyl acetate, acidified ethanol, or supercritical fluids [1, 9, 13-15], ultrasound treatment [16], different combinations of membrane separation processes [17-20], and other emerging technologies such as cloud point extraction [21-23].

Adsorption represents an interesting technology for PC recovery from OMW. It has a relatively simple design, operation, and scale-up. It is characterized by ease of resin regeneration and low operating costs $[24,25]$. Two alternative adsorption mechanisms can be used for PC recovery: simple adsorption on neutral nonionic resins and ion exchange on ionic resins. Both sorbent types were successfully used in several fields $[25,26]$. Several studies focused on the use of these sorbents for the removal of single phenolic compounds from synthetic solutions [27-31]. More recently, adsorption processes were studied to recover valuable compounds from food processing byproducts (PCs, proteins, and peptides) from orange peels, apple pomace, grape seed oil, and pigeon pea [32-36]. In the presence of a complex matrix, such as an actual OMW, PC adsorption yields can be significantly 
reduced by the competitive adsorption exerted by other compounds [37]. In addition, Kammerer et al. [38] showed that carbohydrates and amino acids can reduce PC adsorption yields on both neutral and ion exchange resins. $\mathrm{pH}$ has an important effect on $\mathrm{PC}$ adsorption: low $\mathrm{pH}$ values favour the protonated form and thus the adsorption on neutral resins, whereas higher $\mathrm{pH}$ values (up to 12) favour the corresponding anionic form and therefore adsorption on ion exchange resins [28-30]. Basic $\mathrm{pH}$ values are preferable in the case of ion exchange of PCs which do not contain carboxyl functional group such as tyrosol, hydroxytyrosol, and oleuropein. On the other hand, many PCs are also carboxylic acids. For this reason, PCs were successfully adsorbed via ion exchange also at neutral $\mathrm{pH}$ values [38].

Although several works dealt with PC adsorption, only a few studies focused on the development of continuous flow processes for the adsorption of PC mixtures [39-45]. Among these, only one used an actual OMW [39], whereas the others used other natural sources or synthetic PC mixtures. In other works, OMW adsorption was investigated as a wastewater treatment, rather than a PC recovery process $[18,46]$.

In a previous work [47], our research group tested the feasibility of recovering PCs from actual OMW by adsorption on a $0.5 \mathrm{~m}$ column. The nonionic XAD16 resin was selected on the basis of preliminary tests carried out with 4 resins: nonionic weakly polar acrylic ester Amberlite XAD7, nonionic nonpolar S-DV Amberlite XAD16, polar S-DV IE Amberlite IRA96 (polyamine functional group), and nonpolar hydroxylated polystyrene-divinylbenzene Isolute ENV+ [3, 48, 49]. The previous work [47] included PC isotherms, breakthrough tests followed by desorption with acidified ethanol, process simulation, and the design of a longer adsorption column (2$3 \mathrm{~m}$ ) to be used for further investigations.

The main objectives of this work were the following.

(1) Comparing the PC Separation Capacity of Two Ion Exchange Resins and a Neutral Resin (XAD16), by means of Isotherms and Breakthrough Tests Conducted with Actual $O M W$. Indeed, although XAD16 previously proved to be an efficient and moderately selective sorbent [47], its relatively high cost could affect the economic feasibility of the PC recovery process. On the other hand, ion exchange resins are generally less expensive. For this purpose, a strong and a weak ion exchange resin (IRA958 $\mathrm{Cl}$ and IRA67) were selected.

(2) Evaluating the PC Separation Capacity of Two Ion Exchange Resins and a Neutral Resin (XAD16) in the Absence and in the Presence of Significant Amounts of VFAs and at Different $p H$ Values. Indeed, PC recovery was investigated in the framework of a comprehensive process of OMW valorisation which may comprise several steps, including the conversion of the available COD into volatile fatty acids (VFAs) by anaerobic digestion. In turn, VFAs can be used as carbon source for a variety of purposes, including polyhydroxyalkanoates production [50-52]. In this perspective, PC adsorption can be carried out either before or after VFA production: in the first case, PCs will compete for adsorption with the other nonphenolic compounds present in the OMW, whereas in the second case PCs will compete mainly with VFAs. In both cases, the competitive effect exerted on PC adsorption is strongly affected by $\mathrm{pH}$. Indeed, for both VFAs and PCs, high $\mathrm{pH}$ values shift the equilibrium towards the ionized form and therefore favour adsorption on ion exchange resins, whereas low $\mathrm{pH}$ values enhance adsorption on nonionic resins. However, the $\mathrm{pH}$ threshold above which the ionized form prevails depends on the specific compounds considered: the pKa values of VFAs and of the carboxylic groups that some PCs contain are in the range 4.0-5.0, indicating that at $\mathrm{pH}$ values above 5-6 these compounds are mostly ionized; on the other hand, the phenolic groups have significantly higher pKa values (9.9 for phenol) and therefore get ionized at much higher $\mathrm{pH}$ values. Furthermore, $\mathrm{pH}$ impacts the distribution between the free and the protonated forms of the tertiary amine which functionalizes ion exchange resins such as IRA67. On the other hand, quaternary ammonium groups such as those of IRA958 Cl cannot be protonated. Thus, in this work, both conditions (with and without VFA addition) were tested at three $\mathrm{pH}$ values, from the natural $\mathrm{pH}$ of the fresh OMW (4.9) up to neutrality, in the perspective of a process in which no further $\mathrm{pH}$ correction is required before the final use of the treated water for either irrigation or further biotechnological transformations.

(3) Assembling and Testing a $1.8 \mathrm{~m}$ Adsorption/Desorption Column and Comparing the Experimental Performances Obtained with XAD16 with Those Predicted on the Basis of the Results Previously Obtained in the $0.5 \mathrm{~m}$ Column. Indeed, in our previous work [47], the model-based optimization of PC adsorption on XAD16, performed on the basis of the $0.5 \mathrm{~m}$ tests, showed that a column length in the $1.8-3 \mathrm{~m}$ range was expected to lead to high performances in terms of both PC adsorption yield and resin utilization efficiency.

The main novel elements of this study are (i) the development and modelling of a continuous flow adsorption/desorption process for OMW PC separation, (ii) the comparison of ion exchange and nonionic resins for OMW PC separation, and (iii) the evaluation of the competitive effect exerted by VFAs on PC adsorption.

\section{Materials and Methods}

2.1. OMW, Resin, and Chemicals. The OMWs used in this study were produced by a 3-phase olive mill located near Imperia, in Northwest Italy. Different OMWs relative to three consecutive production years (2012-2014) were used. The main characteristics of the tested OMWs are reported in Table 1 .

Amberlite XAD16 (DOW Chemical Europe GmbH, Horgen, Switzerland) is a nonionic styrene-divinylbenzene adsorption solid phase. Amberlite IRA958 $\mathrm{Cl}$ is a strongly basic anion exchange resin, with a quaternary ammonium functional group in a cross-linked acrylic polymer matrix releasing $\mathrm{Cl}^{-}$in exchange for the dissociated polyphenols or acids. Amberlite IRA67 is a weakly basic anion exchange resin, with a tertiary amine functional group in a crosslinked acrylic gel structure. Both ion exchange resins are 
TABLE 1: Main characteristics of the tested OMWs.

\begin{tabular}{lccc}
\hline & Imperia & Imperia & Imperia \\
& 2012 OMW & 2013 OMW & 2014 OMW \\
\hline Total phenolic compounds (g/L) & 1.6 & 0.51 & 13 \\
Total solids (g/L) & 34 & 5 & 24 \\
Suspended solids (g/L) & 33 & 8 & $\mathrm{a}$ \\
Dissolved solids (g/L) & 1 & 21 & $\mathrm{a}$ \\
COD (g/L) & 32 & 23.0 & 32 \\
Total carbohydrates (g/L) & 5.4 & 1.00 & 16.2 \\
Density $(\mathrm{kg} / \mathrm{L})$ & 1.01 & 4.6 & 1.01 \\
pH & 4.6 & & 4.9 \\
\hline
\end{tabular}

${ }^{\mathrm{a}}$ Parameter not available.

TABLE 2: Technical characteristics of the tested sorbents.

\begin{tabular}{|c|c|c|c|}
\hline & XAD16 & IRA958 Cl & IRA67 \\
\hline Polymeric matrix & Cross-linked styrene/divinylbenzene & Cross-linked acrylic & Cross-linked acrylic gel \\
\hline Physical form & White translucent beads & White opaque beads & White translucent beads \\
\hline Specific density (kg/L) & 1.04 & $1.05-1.08$ & 1.06 \\
\hline Adsorption capacity at saturation & $370 \mathrm{mg} / \mathrm{g}_{\text {dry resin }}{ }^{\mathrm{a}}$ & $0.8 \mathrm{eq} / \mathrm{L}$ & $>1.60 \mathrm{eq} / \mathrm{L}$ \\
\hline Surface area $\left(\mathrm{m}^{2} / \mathrm{g}\right)$ & 800 & $\mathrm{~b}$ & $\mathrm{~b}$ \\
\hline Porosity (dry resin, L/L) & 0.55 & $\mathrm{~b}$ & $\mathrm{~b}$ \\
\hline Average particle size (dry resin, $\mathrm{mm}$ ) & 0.63 & $0.63-0.85$ & $0.50-0.75$ \\
\hline Uniformity coefficient & 2.0 & 1.8 & $<1.8$ \\
\hline Fine content $(\mathrm{mm})$ & $<0.350: 2.0 \% \max$ & $<0.355: 1.0 \% \max$ & $<0.300: 3.0 \% \max$ \\
\hline Coarse content $(\mathrm{mm})$ & $>1.18: 2.0 \% \max$ & $>1.18: 5.0 \% \max$ & $\mathrm{b}$ \\
\hline Maximum reversible swelling & $25 \%$ & $\mathrm{~b}$ & $<30 \%$ \\
\hline
\end{tabular}

${ }^{\mathrm{a}}$ Referring to medium molecular weight compounds.

${ }^{\mathrm{b}}$ Parameter not provided by the resin supplier.

produced by Rohm and Haas Company, Philadelphia, Pennsylvania, USA. The main characteristics of the three resins are described in Table 2.

XAD16 was activated as follows: (i) resin soaking with acidified ethanol $(0.5 \% \mathrm{HCl} 0.1 \mathrm{~N})$, (ii) overnight drying at $105^{\circ} \mathrm{C}$, (iii) second resin soaking with acidified ethanol, and (iv) double washing with demineralized water [49]. Finally, the activation solvent was removed by syringe aspiration and a mass of activated and hydrated resin (28\% w/w resin, $72 \%$ w/w water) was obtained. IRA958 Cl and IRA67 ion exchange resins did not need any activation.

The desorption-regeneration solvent, the HPLC mobile phase components, gallic acid, sodium carbonate, sodium chlorate, sulphuric acid, and the solvents for resin activation were obtained from Sigma-Aldrich (Milan, Italy). The COD Test Tubes were acquired from Aqualytic (Dortmund, Germany).

2.2. Analytical Methods. The total phenolic compounds content was determined by means of an HPLC method using a C18 Kinetex $2.6 \mu \mathrm{m} 100 \AA$ Phenomenex column, a Jasco 880 pump, and a Jasco $875-\mathrm{UV}$ Intelligent UV/vis detector (Easton, Maryland) set at $264 \mathrm{~nm}$. A two-mobile-phase gradient was applied: solvent A was HPLC water with $0.1 \%$ orthophosphoric acid and solvent B was acetonitrile. Gallic acid was used as internal standard $(50 \mathrm{mg} / \mathrm{L})$. Total solid content was measured by drying the sample overnight at $105^{\circ} \mathrm{C}$ and weighing. Suspended solids were determined by filtration with a $0.45 \mu \mathrm{m}$ ALBET cellulose nitrate membrane filter and weighing. Dissolved solids were calculated as the difference between total and suspended solids. COD was measured spectrophotometrically using the Aqualytic COD Vario Tubes (range: $0-1500 \mathrm{mg}_{\mathrm{O} 2} / \mathrm{L}$ ). OMW density was measured by means of a $100 \mathrm{~mL}$ ITI Tooling pycnometer. $\mathrm{pH}$ was measured with an EUTECH Instruments pH 2700 Series $\mathrm{pH}$ meter (Thermo Fisher Scientific, Waltham, Massachusetts). More details on the analytical procedures are reported in [47].

2.3. Adsorption Isotherms. The PC adsorption isotherms were studied in the $27-30^{\circ} \mathrm{C}$ temperature range, approximately corresponding to the operational temperature of the breakthrough experiments. Different amounts (0.1-2.0 g) of dry resin were introduced into $50 \mathrm{~mL}$ glass vials. Two vials were set up for each amount of resin. After adding $20 \mathrm{~mL}$ of OMW, the vials were placed in a rotatory shaker $(140 \mathrm{rpm})$ for $2 \mathrm{~h}$. The equilibrium concentration in the solid phase $C_{S, \mathrm{PC}, \mathrm{eq}}$ was then calculated as $C_{S, \mathrm{PC} \text {,eq }}=\left(C_{L, \mathrm{PC}, 0}\right.$. $\left.V_{L \text {,added }}-C_{L, \mathrm{PC} \text {,eq }} \cdot V_{L \text {,final }}\right) / m_{S}$, where $m_{S}$ is the dry resin mass, $C_{L, \mathrm{PC}, 0}$ and $C_{L, \mathrm{PC}, \mathrm{eq}}$ are the initial and final $\mathrm{PC}$ concentrations in the liquid, and $V_{L \text {,added }}$ and $V_{L \text {,final }}$ are, respectively, the 
OMW volume added to the solid and the final liquid volume resulting from the sum of the added OMW and the water initially contained in the activated resin. In the preliminary tests aimed at selecting one out of the two investigated ion exchange resins (Section 3.1), one single condition of the isotherm was tested, following the same procedure described above for the complete isotherm and mixing $10 \mathrm{~g}$ of dry resin with $20 \mathrm{~mL}$ of OMW. Each single-point test was characterized by means of the PC, COD, and VFA adsorption yield $Y_{\mathrm{ads}, i}$, evaluated as $m_{i, \text { sorbed }} / m_{i \text {,initial }}$.

2.4. OMW Pretreatment. A 3-step OMW pretreatment was used to remove the suspended solids and avoid the adsorption bed fouling: (i) centrifugation of fresh OMW at $4000 \mathrm{rpm}$ for 30 minutes, using a Thermo Fisher Scientific SC16R centrifuge (Waltham, Massachusetts), (ii) in-line $25 \mu \mathrm{m}$ microfiltration, and (iii) in-line $11 \mu \mathrm{m}$ microfiltration (GE Healthcare Life Science Whatman filters). Filtration was performed at a $1 \mathrm{~m} / \mathrm{h}$ superficial velocity. This procedure allowed the removal of $98.5 \%$ of the suspended solids. Only modest and reversible pressure drop increases (from 0.1 to 0.3 bar) were observed during the breakthrough tests. The PC loss with the separated solid resulted to be equal to 7-8\%. More details on the OMW pretreatment are shown in [47].

2.5. Adsorption Column Packing. The semicontinuous adsorption/desorption tests were performed in an adsorber made of $40.5 \mathrm{~m}$ glass columns (inner diameter $0.0244 \mathrm{~m}$ ) connected in series. After placing a $20-25 \mathrm{~mm}$ layer of quartz sand at the bottom, each column was filled with the chosen resin using the dynamic axial compression technique optimized and described in detail previously [47]. $150 \mathrm{~mL}$ of a diluted slurry ( $100 \mathrm{~g}_{\text {dry_resin }} / \mathrm{L}_{\mathrm{DI} \text { water }}$ ) was sonicated for 5 minutes in order to remove the air trapped in the resin beads, poured on the sand layer, and left to natural settling for one hour. After recirculating deionized water downwards until the stable settling of the resin, $25 \mathrm{~mL}$ of a second more concentrated slurry ( $600 \mathrm{~g}_{\text {dry_resin }} / \mathrm{L}_{\text {DI water }}$ ) was sonicated and added in three steps. Further deionized water recirculation was applied and, finally, a further $20-25 \mathrm{~mm}$ quartz sand layer was placed at the top of the resin and the column was flushed downwards overnight with deionized water. Therefore, the actual resin bed length was $1.82 \mathrm{~m}$.

2.6. Fluid-Dynamic Tests. For the best performing resins, frontal analysis experimental tests were carried out to evaluate the packing quality and the fluid-dynamic behavior of the adsorption bed. A $0.04 \mathrm{M} \mathrm{NaCl}$ solution was fed from the top of the column at a superficial velocity of $1.2 \mathrm{~m} / \mathrm{h}$. At the column outlet, the electrical conductivity was measured with an EUTECH Instruments 2700 series conductometer. The packing quality was evaluated by means of the method described in detail in [47], which allowed estimating (i) the number of theoretical plates $N$, (ii) the height equivalent to a theoretical plate (HETP), (iii) the HETP/ $d_{p}$ ratio, where $d_{p}$ indicates the average size of the packing particles, and (iv) the asymmetry factor $A_{S}$, defined as the ratio between the leading and tailing semiwidth of the peak at $10 \%$ of the peak height. For chromatography purposes, $\mathrm{HETP} / d_{p}$ should be as low as possible
$(<3)$ and $A_{S}$ should be as close as possible to $1\left(0.8<A_{S}<\right.$ 1.8) [53]. The same frontal analysis data were used to estimate the effective porosity $(\varepsilon)$ and longitudinal dispersivity $\left(\alpha_{L}\right)$ of the resin packed bed. The former parameter was evaluated directly from the retention times distribution curve, whereas the latter was estimated by best fit of the experimental outlet concentrations with a $1 \mathrm{D}$ convection-dispersion model, assuming that no retardation is present due to adsorption phenomena. The experimental data were simulated with the time-dependent convection/diffusion module of the finite element PDE solver COMSOL Multiphysics 3.5a. The bestfitting value of $\alpha_{L \text {,resin }}$ and the $95 \%$ confidence interval were determined by applying the Gauss-Newton method, following the procedure illustrated by Englezos and Kalogerakis [54] and later adapted to convection-dispersion problems by Zama et al. [55]. More details are available in [47].

\subsection{Adsorption Process: Breakthrough Tests and Simulations.} Three adsorption breakthrough tests were performed at room temperature $\left(24-30^{\circ} \mathrm{C}\right)$ in the $1.8 \mathrm{~m}$ column. The detailed operating conditions of each test are reported in Table 3. These tests were labelled XAD2 $(1.8 \mathrm{~m}, 3.1 \mathrm{~m} / \mathrm{h}$; resin XAD16; Imperia $2013 \mathrm{OMW})$, IRA1 $(1.8 \mathrm{~m}, 2.8 \mathrm{~m} / \mathrm{h}$; resin IRA958 Cl; Imperia 2014 OMW), and IRA2 $(1.8 \mathrm{~m}, 1.3 \mathrm{~m} / \mathrm{h}$; resin IRA958 $\mathrm{Cl}$; Imperia $2014 \mathrm{OMW})$. In each test label, the first number after the test ID indicates the column length, and the second refers to the superficial velocity. The superficial velocities, ranging from $1.3 \mathrm{~m} / \mathrm{h}$ to $3.1 \mathrm{~m} / \mathrm{h}$, were selected on the basis of preliminary optimization performed in the previous work [47]. For comparison purposes, Table 3 includes also one of the tests previously performed with XAD16 in the $0.5 \mathrm{~m}$ column: this test, labelled bt 2 in [47], was renamed XAD1 $(0.5 \mathrm{~m}, 1.4 \mathrm{~m} / \mathrm{h})$ in this work for homogeneity.

The pretreated OMW was fed with a Masterflex L/S 0.1 HP 1-100 RPM peristaltic pump. Both pressure drop and temperature were measured hourly. The total PC and COD concentrations were measured in OMW samples taken every hour from the column exit and every 3 hours from the inlet. The average PC and COD levels at the inlet were used to normalize the corresponding outlet values. The experimental tests were continued up to 20 hydraulic residence times (calculated as $\left.V_{\text {resin }} \cdot \varepsilon_{\text {resin }} / Q+V_{\text {sand }} \cdot \varepsilon_{\text {sand }} / Q\right)$ corresponding to an outlet normalized $\mathrm{PC}$ concentration varying between 0.3 and 0.9. The adsorption performance was quantified by means of the following indexes, referred to a 0.2 dimensionless concentration used as breakpoint value: (i) adsorption yield $\left(Y_{\mathrm{ads}, i}\right)$, evaluated as $m_{i \text {,adsorbed }} / m_{i, \text { fed }}$; (ii) PC/COD adsorption selectivity, expressed as the corresponding adsorption yield ratios; (iii) resin utilization efficiency $\left(\eta_{\text {resin }}\right)$, defined as (PC mass sorbed at the breakthrough point)/(total PC mass that could be sorbed if all the resin was saturated); (iv) PC/COD enrichment factor, defined as the ratio between the PC content in the total COD of the adsorbed matter $\left(\mathrm{g}_{\mathrm{PCs}} / \mathrm{g}_{\mathrm{COD}}\right)$ and that in fresh OMW; (v) resin productivity, expressed as $\mathrm{g}_{\mathrm{PCs} \text { sorbed }} / \mathrm{kg}_{\text {resin }}$. These indexes were calculated as described in [47].

For the best performing resin, the experimental normalized PC and COD breakthrough curves were interpreted by means of a $1 \mathrm{D}$ convection-dispersion model, in order to 
TABLE 3: Experimental conditions, resin and packed bed properties, and adsorption/desorption performances relative to the breakthrough tests.

\begin{tabular}{|c|c|c|c|c|c|}
\hline & \multirow[b]{2}{*}{ Parameter } & \multicolumn{4}{|c|}{ Test ID } \\
\hline & & $\begin{array}{c}\text { XAD1 } \\
(0.5 \mathrm{~m}, 1.4 \mathrm{~m} / \mathrm{h})^{\mathrm{a}}\end{array}$ & $\begin{array}{c}\text { XAD2 } \\
(1.8 \mathrm{~m}, 3.1 \mathrm{~m} / \mathrm{h})\end{array}$ & $\begin{array}{c}\text { IRA1 } \\
(1.8 \mathrm{~m}, 2.8 \mathrm{~m} / \mathrm{h})\end{array}$ & $\begin{array}{c}\text { IRA2 } \\
(1.8 \mathrm{~m}, 1.3 \mathrm{~m} / \mathrm{h})\end{array}$ \\
\hline \multirow{4}{*}{$\begin{array}{l}\text { Resin type and } \\
\text { properties }\end{array}$} & Resin type & XAD16 & XAD16 & IRA958 Cl & IRA958 Cl \\
\hline & Resin bulk density $\left(\rho_{b}, \mathrm{~kg}_{\text {dry resin }} / \mathrm{L}\right)$ & 0.87 & 0.87 & 0.65 & 0.65 \\
\hline & Resin porosity $\left(\varepsilon_{\text {resin }},-\right)$ & 0.83 & 0.89 & 0.53 & 0.55 \\
\hline & Resin long. dispersivity $\left(\alpha_{L, \text { resin }}, \mathrm{m}\right)$ & 0.004 & 0.029 & $\mathrm{~b}$ & $\mathrm{~b}$ \\
\hline \multirow{4}{*}{$\begin{array}{l}\text { Experimental } \\
\text { conditions }\end{array}$} & Bed length $(\mathrm{m})$ & 0.5 & 1.8 & 1.8 & 1.8 \\
\hline & $v_{\text {sup }}(\mathrm{m} / \mathrm{h})$ & 1.4 & 3.1 & 2.8 & 1.3 \\
\hline & $T\left({ }^{\circ} \mathrm{C}\right)$ & 30 & 24 & 29 & 26 \\
\hline & Imperia OMW production year & 2012 & 2013 & 2014 & 2014 \\
\hline \multirow{9}{*}{$\begin{array}{l}\text { Performances } \\
\text { and best-fitting } \\
\text { values of model } \\
\text { parameters }\end{array}$} & PC adsorption yield $\left(Y_{\mathrm{ads}, \mathrm{PC}},-\right)^{\mathrm{c}}$ & $88 \%$ & $92 \%$ & $87 \%$ & $97 \%$ \\
\hline & COD adsorption yield $\left(Y_{\mathrm{ads}, \mathrm{COD}},-\right)^{\mathrm{c}}$ & $75 \%$ & $37 \%$ & $95 \%$ & $96 \%$ \\
\hline & Resin utilization efficiency $\left(\eta_{\text {resin }},-\right)^{c}$ & $12 \%$ & $43 \%$ & $9 \%$ & $30 \%$ \\
\hline & PC desorption yield $\left(Y_{\text {des,PC }},-\right)$ & $74 \%$ & $75 \%$ & $60 \%$ & $51 \%$ \\
\hline & PC/COD enrichment factor $(-)^{c}$ & 1.2 & 2.5 & 0.9 & 1.1 \\
\hline & Productivity $\left(\mathrm{g}_{\text {sorbed PC }} / \mathrm{kg}_{\text {resin }}\right)^{\mathrm{c}}$ & 3.4 & 7.6 & 2.1 & 0.9 \\
\hline & $k_{L} a \cdot 10^{3}(1 / \mathrm{s})$ & $2.5 \pm 0.2$ & $3.1 \pm 0.5$ & $\mathrm{~b}$ & $\mathrm{~b}$ \\
\hline & $K_{\text {eq }, \mathrm{PC}}\left(\mathrm{L}_{\text {pore volume }} / \mathrm{kg}_{\text {dry resin }}\right)$ & $85 \pm 2$ & $110 \pm 10$ & $\mathrm{~b}$ & $\mathrm{~b}$ \\
\hline & $K_{\text {eq, }, \mathrm{COD}}\left(\mathrm{L}_{\text {pore volume }} / \mathrm{kg}_{\text {dry resin }}\right)$ & $11 \pm 2$ & $19 \pm 4$ & $\mathrm{~b}$ & $\mathrm{~b}$ \\
\hline
\end{tabular}

${ }^{\mathrm{a}}$ Test XAD1 corresponds to test bt2 in [47].

${ }^{\mathrm{b}}$ Estimates not available, as the simulations were performed only on the best performing resin, XAD16.

${ }^{\mathrm{c}}$ Evaluated at a $20 \%$ PC outlet normalized concentration.

evaluate the process performance and to set up the basis for model-based optimization and scale-up of the process. The model was developed, successfully tested, and applied in the previous work [47] on experimental data collected in a $0.5 \mathrm{~m}$ column. The simulation was conducted under the hypothesis of not negligible mass-transfer resistance. The normalized outlet PC and COD concentrations were interpreted with the mass balance equations relative to the liquid (see (1)) and solid (see (2)) phases as follows:

$$
\begin{aligned}
\frac{\partial C_{L, i}}{\partial t}=-v_{\mathrm{int}} & \cdot \frac{\partial C_{L, i}}{\partial z}+D_{\mathrm{eq}} \cdot \frac{\partial^{2} C_{L, i}}{\partial z^{2}}-k_{L} a \\
& \cdot\left(C_{L, i}-\frac{C_{S, i}}{K_{\mathrm{eq}, i}}\right), \\
\frac{\rho_{b}}{\varepsilon} \cdot \frac{\partial C_{S, i}}{\partial t}= & k_{L} a \cdot\left(C_{L, i}-\frac{C_{S, i}}{K_{\mathrm{eq}, i}}\right),
\end{aligned}
$$

where $C_{L, i}$ indicates the PC or COD liquid phase concentration, $C_{S, i}$ is the corresponding solid phase concentration $\left(\mathrm{g}_{i} / \mathrm{g}_{\text {dry resin }}\right), k_{L} a$ is the mass-transfer coefficient referred to liquid volume, $\rho_{b}$ is the sand or resin bulk density (calculated as mass of dry sand or resin divided by the volume of the corresponding column portion), $\varepsilon$ is the resin or sand porosity, $K_{\mathrm{eq}, i}$ is the PC or COD equilibrium adsorption constant, and $D_{\mathrm{eq}}$ is the equivalent diffusion coefficient (calculated as $\alpha_{L} \cdot v_{\text {int }}$, with the longitudinal dispersivity $\alpha_{L}$ estimated from the fluid-dynamic tests).
In this model, internal and external mass-transfer phenomena are expressed by means of an overall volumetric coefficient [56]. On the basis of the results of the isotherm tests, a linear equilibrium model was utilized in the expression of the mass-transfer driving force. The same $k_{L} a$ value was assumed to be valid for PCs and COD. In these simulations, simple convection with dispersion was assumed for the inert sand added at the bottom and top of each sorbent column (no adsorption on the sand). $K_{\mathrm{eq}, \mathrm{PC}}$ and $k_{L} a$ were estimated by best-fit procedure on the experimental PC concentrations following the Gauss-Newton method, according to the procedure for its adaptation to convection-dispersion problems illustrated by Zama et al. [55]. Similarly, $K_{\text {eq, COD }}$ was estimated by best-fit procedure on the experimental COD concentrations. The quality of each best fit was evaluated by means of the correlation coefficient $R^{2}$ as defined in [57]. More details on the model and on the best-fit procedure are reported by Frascari et al. [47].

2.8. Desorption-Regeneration Tests. To desorb and recover PCs, at the end of each semicontinuous breakthrough adsorption test, acidified ethanol $(0.5 \% \mathrm{v} / \mathrm{v} \mathrm{HCl} 0.1 \mathrm{~N})$ was fed from the bottom of the column with a Masterflex L/S 0.1 HP -1-100 RPM pump. The solvent flow rate was initially equal to the OMW flow rate in the corresponding adsorption test. However, a gradual decrease in solvent flow rate was applied to maintain the total pressure at the column inlet $<2$ bar, as solvent viscosity increased due to the increase in PC dissolved concentration. Desorption was continued 
TABLE 4: Single-point adsorption test: $\mathrm{pH}$-averaged adsorption yields relative to the 3 tested resins, with standard deviations.

\begin{tabular}{lcccc}
\hline Resin & VFA content $(\mathrm{g} / \mathrm{L})$ & $Y_{\text {ads, PC }}$ & $Y_{\text {ads, COD }}$ & $Y_{\text {ads, VFA }}$ \\
\hline \multirow{2}{*}{ XAD16 } & 1.3 (no VFA addition) & $77 \% \pm 3 \%$ & $71 \% \pm 10 \%$ & $72 \% \pm 1 \%$ \\
& 10.3 (with VFA addition) & $83 \% \pm 7 \%$ & $44 \% \pm 14 \%$ & $43 \% \pm 19 \%$ \\
\hline \multirow{2}{*}{ IRA958 Cl } & 1.3 (no VFA addition) & $60 \% \pm 5 \%$ & $31 \% \pm 7 \%$ & $43 \% \pm 3 \%$ \\
& 10.3 (with VFA addition) & $55 \% \pm 10 \%$ & $38 \% \pm 4 \%$ & $46 \% \pm 7 \%$ \\
\hline \multirow{2}{*}{ IRA67 } & 1.3 (no VFA addition) & $33 \% \pm 12 \%$ & $17 \% \pm 5 \%$ & $22 \% \pm 2 \%$ \\
& 10.3 (with VFA addition) & $34 \% \pm 23 \%$ & $31 \% \pm 11 \%$ & $37 \% \pm 23 \%$ \\
\hline
\end{tabular}

until the attainment of a PC concentration $<5 \%$ of the average inlet concentration during the adsorption step. This criterion was fulfilled with a total desorption time equal to about 5 hydraulic residence times. Finally, the column was rinsed with demineralized water for at least 5 hydraulic residence times. The PC desorption yield $Y_{\text {des,PC, defined }}$ as $m_{\mathrm{PC} \text {,desorbed }} / m_{\mathrm{PC} \text {,sorbed }}$, was determined on the basis of the PC content of the ethanol solution and of the rinsing water solution. To regenerate the solvent and recover the desorbed compounds, the desorbed ethanolic extract was fed to a low-pressure distillation process in a rotatory evaporator (LABOROTA 4002 Heidolph, Schwabach, Germany). Further details on the desorption tests are reported in [47]. The above-described desorption procedure, developed and successfully tested for XAD16 in the previous work [47], was tentatively applied to IRA958 $\mathrm{Cl}$ as well.

\section{Results and Discussion}

3.1. Comparison of the Performances of Nonionic and Ion Exchange Resins by means of Batch Tests. A first set of equilibrium tests was carried out to compare the PC adsorption performances of the selected sorbents (IRA67, IRA958 Cl, and $\mathrm{XAD} 16)$ and in particular to choose the best performing ion exchange resin between IRA67 and IRA958 Cl. As described in Section 2.3 for the single-point isotherm tests, $20 \mathrm{~mL}$ of OMW was mixed with $10 \mathrm{~g}$ of dry resin. In the complete isotherm previously performed with XAD16 [47], this condition yields a low concentration point, corresponding to a dimensionless PC concentration of about 0.1 . In actual industrial processes, this represents the typical threshold at the column outlet used to stop the adsorption phase (breakpoint).

The fresh Imperia 2014 OMW contains $1.3 \mathrm{~g} / \mathrm{L}$ of VFAs (acetic acid $0.60 \mathrm{~g} / \mathrm{L}$, propionic acid $0.02 \mathrm{~g} / \mathrm{L}$, butyric acid $0.63 \mathrm{~g} / \mathrm{L}$, and valeric acid $0.03 \mathrm{~g} / \mathrm{L})$. On the other hand, VFA concentration can be much larger if the OMW is pretreated in an acidogenic anaerobic digestion process aimed at turning the nonphenolic COD into VFAs. In order to study the possible interference of VFAs on PC adsorption, the tests at different $\mathrm{pH}$ values $(4.9,6$, and 7.2$)$ were repeated after the addition of a VFA mixture whose composition mimicked that of a typical effluent of a process of OMW acidogenic anaerobic digestion [58]: acetic acid $4.26 \mathrm{~g} / \mathrm{L}$, propionic acid $1.61 \mathrm{~g} / \mathrm{L}$, butyric acid $3.42 \mathrm{~g} / \mathrm{L}$, valeric acid $0.97 \mathrm{~g} / \mathrm{L}$, and total VFAs $10.3 \mathrm{~g} / \mathrm{L}$.

The $\mathrm{pH}$-averaged adsorption yields obtained with and without VFA addition are shown in Table 4. These average values can be used to compare the performance of the tested sorbents also in terms of PC/COD and PC/VFA selectivity and to discuss the influence of VFAs on PC adsorption.

In all the experimental conditions, XAD16 performed better than both tested ion exchange resins, with average PCs adsorption yields between $77 \%$ and $83 \%$, whereas IRA958 $\mathrm{Cl}$, the best of the two ion exchange resins, ranged between $55 \%$ and $60 \%$. Even if XAD16 confirmed its high PC affinity, the average XAD16 yields for PCs, COD, and VFAs were very similar (77\%, $71 \%$, and $72 \%$, resp.), indicating seemingly poor PC/COD selectivity. The low selectivity of XAD16 in these tests is in apparent contradiction with the results of our previous work [47]. A tentative explanation of this incongruence will be discussed in Section 3.2 on the basis of the isotherm data. On the other hand, both ion exchange resins seem to possess a lower PC capacity than XAD16 but higher PC selectivity: for example, IRA958 $\mathrm{Cl}$ adsorbs $60 \%$ of PCs with no VFA addition but only $31 \%$ of COD and $43 \%$ of VFAs.

VFAs did not significantly hinder PC adsorption. Indeed, for all the tested resins, the PC yields obtained with and without VFA addition were equivalent. On the other hand, VFA addition determined a marked increase in the PC selectivity of XAD16 (both PC/COD and PC/VFAs yield ratios increased from 1.1 to 1.9), as a result of the decreases in COD and VFA yields. In fact, notwithstanding a 30\% increase of COD due to VFA addition, the amount of COD adsorbed on XAD16 in the test with VFA addition is very close to that without addition ( $450 \mathrm{mg}$ without addition, $370 \mathrm{mg}$ with addition). On the contrary, a 10-fold increase of the initial VFA concentration (from $1.3 \mathrm{~g} / \mathrm{L}$ to $10.3 \mathrm{~g} / \mathrm{L}$ ) led to a 5 -fold increase of the adsorbed VFAs (from $19 \mathrm{mg}$ to $88 \mathrm{mg}$ ). These data suggest that, in XAD16, COD is close to the saturation zone of a theoretical Langmuir type isotherm both in the raw OMW and in the samples with VFA addition, whereas VFAs reach saturation only after the increase in their concentration. Notwithstanding these marked changes in concentration of possible competitors, PCs are sorbed on XAD16 with similar yields, suggesting that PC and VFA adsorption occur without competition.

As for the effect of $\mathrm{pH}$, the PC, COD, and VFA adsorption yields obtained with and without VFA addition at each tested $\mathrm{pH}(4.9,6.0$, and 7.2$)$ are reported in Figure S1 in the Supplementary Material available online at http://dx.doi.org/10.1155/ 2016/9349627. pH seems to have a little effect on the adsorption performance in the tested range. In particular, no significant influence was seen on XAD16, both in the absence and in the presence of high VFA concentrations. This behavior is somehow expected as XAD16 is a nonionic resin and PCs are predominantly protonated at acidic $\mathrm{pH}$. 
On the contrary, opposite effects of $\mathrm{pH}$ were observed on the ion exchange resins. In the case of IRA $958 \mathrm{Cl}$ (quaternary ammonium functionalized), a moderate increase of the PC yield was achieved by increasing $\mathrm{pH}$ from 4.9 to 7.2 , both in the fresh OMW (from 54\% to 64\%) and in the samples with VFAs addition (from $44 \%$ to $64 \%$ ). This result may be ascribed to the increase of the ionized PC fraction with increasing $\mathrm{pH}$. On the other hand, the $\mathrm{pH}$ increase determined decay in the PC yields obtained with IRA67 (tertiary amine functionalized): from $47 \%$ to $23 \%$ with the fresh OMW and from $60 \%$ to $22 \%$ in the presence of VFA addition. This negative influence can be tentatively explained taking into account the protonation equilibrium of the tertiary amine: at relatively low $\mathrm{pH}$, the prevailing protonated form allows ion exchange to effectively adsorb PCs, whereas at neutral $\mathrm{pH}$ the nonionic form of the amine is likely to dominate, and adsorption occurs by simple interaction with the polymeric matrix. However, acidic conditions significantly reduce the PC ionic form that can be retained by an ion exchange mechanism.

In conclusion, the performances of both tested IRA ion exchange resins are lower than those of XAD16 in terms of PC adsorption capacity, even if higher in selectivity for PCs in the specific tested condition. In particular, the lower affinity of the IRA ion exchange resins for VFAs may result to be interesting in case of a process of PC adsorption after conversion of the nonphenolic COD into VFAs by means of acidogenic anaerobic digestion. On the basis of these results, IRA958 $\mathrm{Cl}$, the best performing of the two ion exchange resins, was selected for a further investigation of its performances, consisting in a complete isotherm curve and in breakthrough tests in the $1.8 \mathrm{~m}$ adsorbing bed.

3.2. Polyphenol Adsorption Isotherms. The PC isotherms relative to IRA958 $\mathrm{Cl}\left(T=30^{\circ} \mathrm{C}\right)$ and XAD16 $\left(T=27^{\circ} \mathrm{C}\right)$ are shown in Figure 1 in terms of solid and liquid phase equilibrium concentrations and interpolation curves. In the case of XAD16, the experimental equilibrium points can be divided into two zones: first a low concentration zone (up to $150 \mathrm{mg} / \mathrm{L}$ in the liquid) with an unfavourable behavior and second a medium-high concentration zone where a linear trend is observed. The latter could be interpreted as the initial linear part of a Langmuir isotherm. This hypothesis is supported by the observation that the theoretical XAD16 capacity $\left(370 \mathrm{mg} / \mathrm{g}_{\text {dry resin }}\right)$ is about 6 times higher than the maximum sorbed concentration measured in this work. This peculiar behavior of XAD16, observed also at different temperatures [47] and with different OMWs (data not published), can be tentatively ascribed to the competitive adsorption of the single PCs and of other COD components. Overall, a linear interpolation of the XAD16 isotherm resulted in a high $R^{2}$ (0.94). Therefore, a linear adsorption model was successfully used in the simulation of the XAD16 breakthrough tests, as illustrated in Section 3.4. On the other hand, the IRA958 $\mathrm{Cl}$ experimental points show an unfavourable behavior throughout the entire PC concentration range. The IRA958 $\mathrm{Cl}$ isotherm was interpolated by means of a power-law curve (Freundlich type isotherm) with an exponent higher than 1 $\left(R^{2}=0.88\right)$.

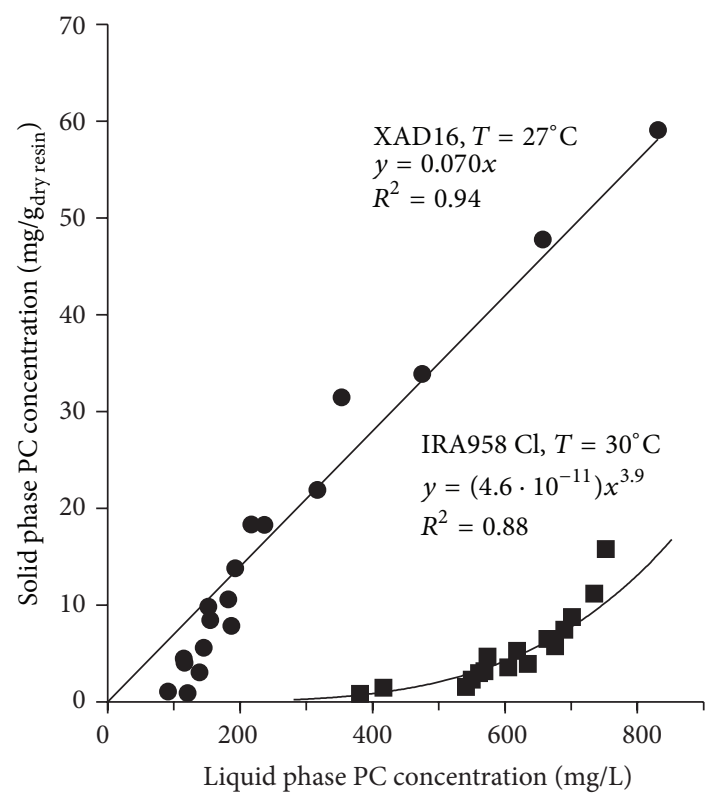

FIGURE 1: Isotherm tests conducted with resins XAD16 and IRA958 $\mathrm{Cl}$ : experimental data and best-fitting interpolations.

It should be noted that, for both XAD16 and IRA958 $\mathrm{Cl}$, the single-point equilibrium experiments, object of Section 3.1, are at the very beginning of the isotherms, in the unfavourable behavior zone (resp., 72 and $350 \mathrm{mg} / \mathrm{L}$ of PC liquid concentration, 1.2 and $0.82 \mathrm{mg} / \mathrm{g}_{\text {dry resin }}$ of sorbed concentration). This evidence explains the low selectivity observed in the single-point experiment with XAD16, as the PC sorbed amount is five times lower than the amount that would be expected if the linear trend observed at higher liquid concentration was applicable also in this low concentration zone.

In conclusion, regardless of the different isotherm type and the slight difference in temperature, the comparison of the experimental data clearly shows that the IRA958 Cl PC adsorption performance is significantly worse than that of XAD16, at least at the PC concentrations typical of the tested OMWs. The comparison between IRA958 Cl and XAD16 was completed by means of fluid-dynamic and breakthrough tests conducted in the $1.8 \mathrm{~m}$ adsorption column, in order to assess the $\mathrm{PC} / \mathrm{COD}$ selectivity in a continuous process.

3.3. Fluid-Dynamic Characterization. Before each group of PC breakthrough tests illustrated in Table 3 , the 4 columns of the adsorption bed were packed with fresh resin (XAD16 or IRA958 Cl) and a fluid-dynamic test with $\mathrm{NaCl}$ as tracer was performed in order to evaluate the packing quality, the resin porosity, and, only for XAD16, the longitudinal dispersivity. Some representative cases of the experimental dimensionless $\mathrm{NaCl}$ concentrations at the column exit are shown in Figure 2. The results of the packing quality evaluation are reported in Table 5, whereas the estimated porosities and longitudinal dispersivities are reported in Table 3.

With regard to XAD16, the fluid-dynamic test performed before breakthrough test XAD2 $(1.8 \mathrm{~m}, 3.1 \mathrm{~m} / \mathrm{h})$ resulted in 
TABLE 5: Packing quality assessment on the basis of the fluid-dynamic tests.

\begin{tabular}{lcccc}
\hline Test ID & $N^{\mathrm{b}}(-)$ & HETP $^{\mathrm{c}}$ & $\mathrm{HETP}_{d_{p}}{ }^{\mathrm{d}}(-)$ & $A_{S}{ }^{\mathrm{e}}(-)$ \\
\hline Before XAD2 $(1.8 \mathrm{~m}, 3.1 \mathrm{~m} / \mathrm{h})$ & 120 & 0.017 & 27 & 58 \\
After XAD2 $(1.8 \mathrm{~m}, 3.1 \mathrm{~m} / \mathrm{h})$ & 57 & 0.037 & 61 & 1.3 \\
Before IRA1 $(1.8 \mathrm{~m}, 2.8 \mathrm{~m} / \mathrm{h})$ & 46 & 0.045 & 99 & 1.3 \\
After IRA2 $(1.8 \mathrm{~m}, 1.3 \mathrm{~m} / \mathrm{h})$ & 29 & 0.073 & 99 \\
\hline
\end{tabular}

${ }^{a}$ The fluid-dynamic tests were performed at a $1.2 \mathrm{~m} / \mathrm{h}$ superficial velocity. The velocities reported in the test ID refer to the PC breakthrough test performed before or after each fluid-dynamic test.

${ }^{\mathrm{b}}$ Number of theoretical plates in the column packing (-).

${ }^{\mathrm{c}}$ Height equivalent to a theoretical plate $(\mathrm{m})$.

${ }^{\mathrm{d}}$ HETP/average size of the packing particles (-).

${ }^{\mathrm{e}}$ Asymmetry factor (-).

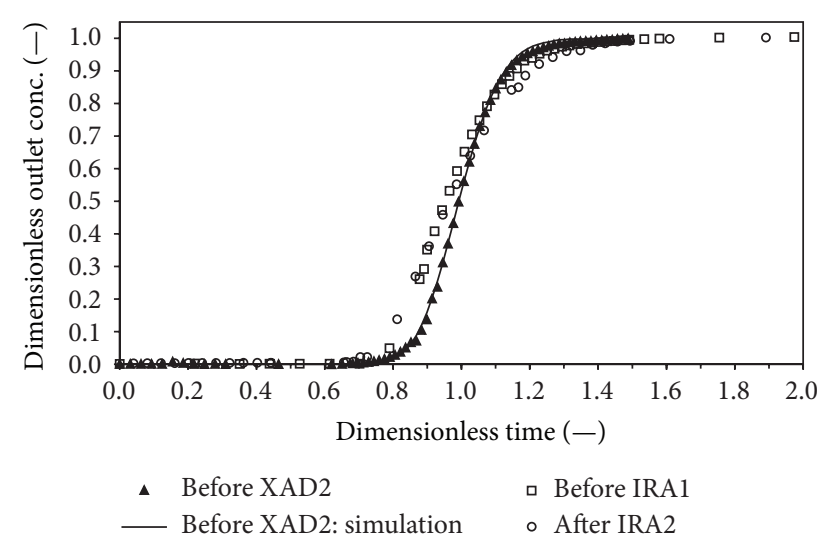

FIGURE 2: Fluid-dynamic tests conducted in the $1.8 \mathrm{~m}$ column: experimental points and, only for resin XAD16, best-fitting simulation.

a high packing quality (very high $N$, low $\mathrm{HETP} / d_{p}$, and asymmetry factor very close to 1$)$. The axial dispersion model with no adsorption and mass transfer (see (1) with $k_{L} a=$ 0 ) fits the data very well $\left(R^{2}=0.98\right.$; continuous line in Figure 2). The quite low longitudinal dispersivity estimated $\left(\alpha_{L}=29 \mathrm{~mm}\right)$ confirms the high packing quality. As shown in Table 5, the fluid-dynamic test performed on the same adsorption bed after one adsorption/desorption cycle resulted on the one hand in doubling of HETP/ $d_{p}$ but on the other hand in a more symmetrical curve. The corresponding curve is not shown in Figure 2 as it is closely overlapped to that measured before test XAD2. This result indicates that the adsorption/desorption cycle has a small but not negligible impact on the packing quality. Further tests are in progress in order to evaluate this aspect in the long term, in the perspective to develop a process characterized by a high number of cycles performed with the same resin.

As a representative case of IRA958 $\mathrm{Cl}$ tests, the tracer curves obtained before the IRA breakthrough tests and after two adsorption/desorption cycles (i.e., after test IRA2) are shown in Figure 2. As shown in Table 5, the operation of 2 consecutive adsorption/desorption cycles with IRA958 Cl led to a $60 \%$ increase of reduced plate height and a $40 \%$ increase of asymmetry factor. This finding confirms that further research is needed to evaluate the impact of repeated adsorption cycles on the packing quality and stability. Interestingly, despite the relevant changes in packing quality between the two abovementioned IRA tests, the experimental trends of the outlet tracer concentration appear to be almost overlapped (Figure 2). This observation enlightens the high sensitivity of the proposed packing quality assessment tool.

3.4. Phenolic Compounds and COD Breakthrough Tests. In our previous work [47], the XAD16 breakthrough tests conducted in a $0.5 \mathrm{~m}$ column at superficial velocities of 0.48 and $1.4 \mathrm{~m} / \mathrm{h}$ resulted in an early breakpoint, in a consequent poor resin utilization efficiency (12\%-17\%), and in the modelbased identification of the optimal bed length (between 2 and $4 \mathrm{~m}$ ). The PC breakthrough curve and the main process performances obtained in the previous work [47] in the $1.4 \mathrm{~m} / \mathrm{h}$ test, relabelled XAD1 $(0.5 \mathrm{~m}, 1.4 \mathrm{~m} / \mathrm{h})$ in this work, are reported in Figure 3(a) and in Table 3 for comparison purposes.

In the present work, the breakthrough test performed with XAD16 at $3.1 \mathrm{~m} / \mathrm{h}$ in the $1.8 \mathrm{~m}$ plant (XAD2, Table 3) was characterized by an increase of both resin bed length (from 0.5 to $1.8 \mathrm{~m}$ ) and superficial velocity (from 1.4 to $3.1 \mathrm{~m} / \mathrm{h}$ ), with a resulting increase in hydraulic residence time (from 0.35 to $0.60 \mathrm{~h}$ ). The $3.1 \mathrm{~m} / \mathrm{h}$ superficial velocity was chosen as a compromise to decrease the mass-transfer resistance without decreasing the residence time, a key factor in the determination of the resin utilization efficiency. The main objective of test XAD2 was to compare the performances with those achieved in the $0.5 \mathrm{~m}$ column (XAD1, $1.4 \mathrm{~m} / \mathrm{h}$ ). The normalized PC and COD concentrations obtained at the column outlet in XAD2 $(1.8 \mathrm{~m}, 3.1 \mathrm{~m} / \mathrm{h})$ are plotted in Figure 3(a) versus dimensionless time, defined as (actual breakthrough time)/(hydraulic residence time).

The simulations of the breakthrough curves were conducted using the axial dispersion model under the hypothesis of not negligible mass-transfer resistance and linear isotherm for both PCs and COD (see (1) and (2)). This approach led both groups of compounds to satisfactory simulations, with $R^{2}=0.95$ for PCs and 0.94 for COD. The bestfitting estimates of $K_{\text {eq,PC }}, K_{\text {eq, COD }}$, and $k_{L} a$ are reported in Table 3. The Gauss-Newton method utilized to estimate these parameters converged after 6-7 iterations and provided acceptably small $95 \%$ confidence intervals. $k_{L} a$ of XAD2 $(1.8 \mathrm{~m}, 3.1 \mathrm{~m} / \mathrm{h})$ resulted to be $25 \%$ higher than that of XAD1 


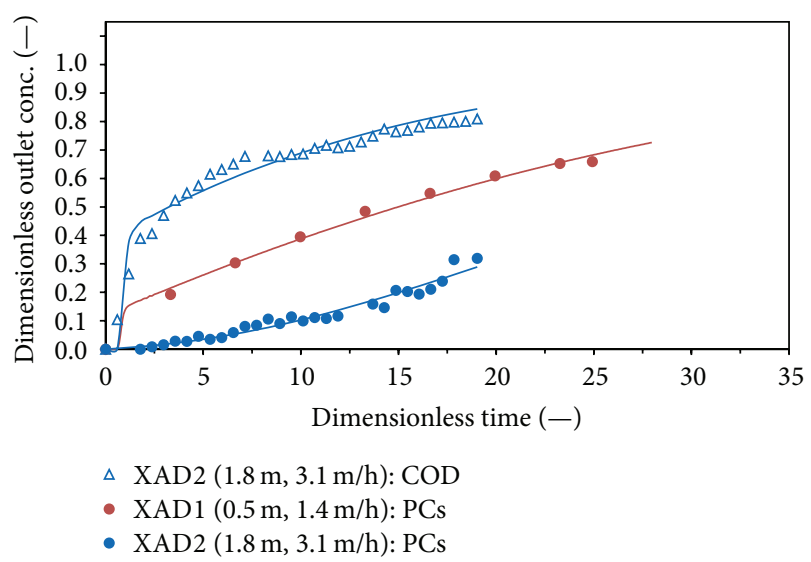

(a) Resin XAD16

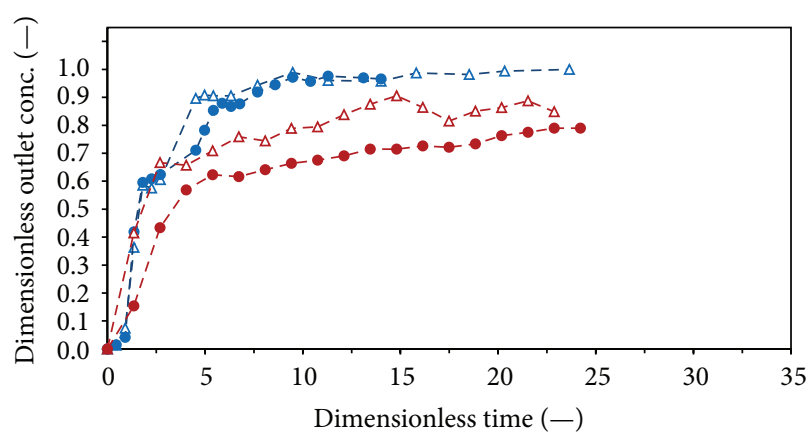

$-\Delta-\operatorname{IRA} 2(1.8 \mathrm{~m}, 1.3 \mathrm{~m} / \mathrm{h}): \mathrm{COD} \quad-\Delta-\operatorname{IRA} 1(1.8 \mathrm{~m}, 2.8 \mathrm{~m} / \mathrm{h}): \mathrm{COD}$

-- IRA2 (1.8 m, $1.3 \mathrm{~m} / \mathrm{h}):$ PCs $\quad \bullet$ IRA1 $(1.8 \mathrm{~m}, 2.8 \mathrm{~m} / \mathrm{h}):$ PCs

(b) Resin IRA958 Cl

FIgure 3: (a) PC and COD breakthrough tests conducted with resin XAD16 in the $0.5 \mathrm{~m}$ column (XAD1, $1.4 \mathrm{~m} / \mathrm{h}$ ) and in the $1.8 \mathrm{~m}$ column $(\mathrm{XAD} 2,3.1 \mathrm{~m} / \mathrm{h})$; the continuous lines indicate the best-fitting simulations performed with (1) and (2); (b) PC and COD breakthrough tests conducted with resin IRA958 $\mathrm{Cl}$ in the $1.8 \mathrm{~m}$ column (IRA1, $2.8 \mathrm{~m} / \mathrm{h}$; IRA2, $1.3 \mathrm{~m} / \mathrm{h}$ ); no simulations were performed for the IRA tests.

$(0.5 \mathrm{~m}, 1.4 \mathrm{~m} / \mathrm{h})$ as a result of the 2 -fold increase in velocity. A $30 \%$ increase in $K_{\text {eq,PC }}$ was observed, probably due to the lower temperature $\left(24^{\circ} \mathrm{C}\right.$ for XAD2 versus $30^{\circ} \mathrm{C}$ for XAD1). On the other hand, the $K_{\text {eq, COD }} / K_{\text {eq, PC }}$ ratio of XAD2 $(0.17 \pm$ $0.04)$ was analogous to that obtained in XAD1 $(0.13 \pm 0.02)$, confirming the high selectivity of XAD16 for PCs evaluated previously [47]. These results show that the apparently low PC/COD selectivity obtained for XAD16 in the single-point batch tests (Section 3.1) was due to the fact that the use of a high resin/OMW ratio led to an equilibrium point falling in the initial portion of the XAD16 isotherm (Figure 1), characterized by an unfavourable behavior.

The PC and COD simulated curves of test XAD2 $(1.8 \mathrm{~m}$, $3.1 \mathrm{~m} / \mathrm{h}$ ), shown in Figure 3(a), were used to estimate the corresponding adsorption yields $\left(Y_{\mathrm{ads}, \mathrm{PC}}\right.$ and $\left.Y_{\mathrm{ads}, \mathrm{COD}}\right)$ and the resin utilization efficiency $\left(\eta_{\text {resin }}\right)$ at the selected $20 \%$ breakpoint (Table 3). As expected, the deeper adsorption bed shifted the experimental curve towards higher dimensionless times, with a considerable enhancement of performance in terms of resin utilization efficiency $(+260 \%$, in comparison with XAD1), a key factor for the economic feasibility of the process. The performances of test XAD2 $(1.8 \mathrm{~m}, 3.1 \mathrm{~m} / \mathrm{h})$ were compared to those expected for a $1.8 \mathrm{~m}$ column filled with XAD16 on the basis of the predictions made in our previous work [47]. While the PC adsorption yields are very close (92\% versus 95\%), the actual resin efficiency (43\%) resulted to be lower than the predicted one (58\%). This deviation can be explained by considering that the higher velocity of test XAD2 $(3.1 \mathrm{~m} / \mathrm{h})$ in comparison with that used for the model predictions $(1.4 \mathrm{~m} / \mathrm{h})$ determines a lower residence time and therefore a lower $\eta_{\text {resin }}$. An optimization of the superficial velocity is in progress.

A second breakthrough test, labelled IRA1 $(1.8 \mathrm{~m}$, $2.8 \mathrm{~m} / \mathrm{h}$ ), was carried out after packing the column with IRA958 $\mathrm{Cl}$ resin. The operating conditions were similar to those of test XAD2 $(1.8 \mathrm{~m}, 3.1 \mathrm{~m} / \mathrm{h})$. The PC and COD experimental data are shown in Figure $3(\mathrm{~b})$. The outlet
PC concentration increased steeply, reaching high levels in less than 5 residence times. The corresponding COD breakthrough curve had a similar trend and resulted to be much closer to the PC curve than in the case of the XAD16 test (XAD2). These data suggest that IRA958 $\mathrm{Cl}$ has very poor PC/COD selectivity. This conclusion is confirmed by the fact that, in test IRA1, the COD yield resulted to be higher than the PC yield (Table 3). Furthermore, the resin utilization efficiency was definitely too low (9\%).

As the performance of IRA958 $\mathrm{Cl}$ was far below the expected, a third breakthrough test (IRA2, $1.8 \mathrm{~m}, 1.3 \mathrm{~m} / \mathrm{h}$ ) was characterized by halving of the surface velocity. This change doubles the residence time, with an expected positive influence on the resin utilization efficiency. On the other hand, the reduction in surface velocity could negatively affect the masstransfer coefficient and therefore the overall performance. As shown in Figure 3(b) and Table 3, in IRA2 $(1.8 \mathrm{~m}, 1.3 \mathrm{~m} / \mathrm{h})$, the PC outlet concentration increased more steeply than in IRA1 $(1.8 \mathrm{~m}, 2.8 \mathrm{~m} / \mathrm{h})$ and rapidly reached the saturation condition. The PC/COD selectivity resulted again to be very poor. Despite an increase in resin efficiency, this parameter still resulted to be $30 \%$ lower than the value obtained with XAD16. Overall, test IRA2 $(1.8 \mathrm{~m}, 1.3 \mathrm{~m} / \mathrm{h})$ confirmed the unsatisfactory PC adsorption capacity of resin IRA958 Cl.

3.5. Desorption-Regeneration Tests, Extract Purity, and Resin Productivity. After every breakthrough test, the adsorbed matter was desorbed from the resin by feeding and recovering acidified ethanol $(0.5 \% \mathrm{v} / \mathrm{v} \mathrm{HCl} 0.1 \mathrm{~N})$. Then, the column was regenerated by demineralized water rinsing. The PC desorption yield, calculated on the basis of the analysis of the ethanol and water extracts, resulted to be equal to about $75 \%$ in both XAD16 tests (short and long column; Table 3). In the two IRA958 Cl tests, the desorption yields were lower (50-60\%) and $1 / 3-1 / 2$ of the desorbed PCs were found in the rinsing water. These results indicate that the desorption procedure developed for XAD16 is not suitable for IRA958 Cl, even if 
other authors used alcoholic solutions to desorb PCs from ion exchange resins $[32,59]$. However, due to the unsatisfactory adsorption results obtained with IRA958 $\mathrm{Cl}$, a desorption protocol specifically adapted to this resin was not developed.

The PC and COD amounts adsorbed in the XAD and IRA tests were calculated and compared to the corresponding values in fresh OMW. This allowed the evaluation of a $\mathrm{PC} / \mathrm{COD}$ enrichment factor, which assesses the effectiveness of the adsorption process in concentrating PCs in the organic matter produced (Table 3). In the XAD16 tests, the use of the $1.8 \mathrm{~m}$ bed (test XAD2) proved necessary in order to attain an acceptable enrichment factor (2.5). On the other hand, the lack of selectivity of IRA958 $\mathrm{Cl}$ did not yield any significant increase in relative $\mathrm{PC} / \mathrm{COD}$ concentration in either IRA test. Working with XAD4 neutral adsorption resin, Zagklis et al. [18] found enrichment factors similar to those attained in test XAD2 $(1.8 \mathrm{~m}, 3.1 \mathrm{~m} / \mathrm{h})$. They succeeded in partially circumventing the problem of coadsorption by applying twostep desorption: the first water washing eluted half of the adsorbed carbohydrates and only $14 \%$ of the PCs, whereas a rich $\mathrm{PC}$ fraction was recovered with ethanol.

A preliminary characterization of the PC/COD extract obtained from Imperia OMW with resin XAD16 indicated that (i) carbohydrate concentration in the OMW was reduced from 23 to $7 \mathrm{~g} / \mathrm{L}$, whereas proteins were completely adsorbed; (ii) in the desorbed product, the nonphenolic COD was composed of carbohydrates (84\%) and proteins (16\%); (iii) preliminary evaluations of the antioxidant power of an extract characterized by a $0.08-0.10$ PC mass fraction resulted in a quite high antioxidant capacity (20-25 mM ascorbic acid equivalent) [47].

The possible need and design of a further purification step to be applied to the desorbed product depend on the specifications requested. Different purification technologies can be applied to separate the nonphenolic COD and thus to obtain a PC-rich product. Several membrane technologies can be applied to concentrate PCs, to separate them from proteins, and to separate high molecular weight PCs from low molecular weight ones [60-63]. Specific high-value PCs such as tyrosol and hydroxytyrosol can also be recovered by means of molecular fingerprinting adsorption processes, characterized by the use of polymers with highly selective sorption sites [11, 64, 65].

Finally, in the perspective of an economic feasibility assessment, an important parameter is the resin productivity, expressed as grams of PCs adsorbed in each adsorption/desorption cycle per $\mathrm{kg}$ of dry resin. This parameter allows taking into account the significant difference in bulk density between XAD16 and IRA958 $\mathrm{Cl}$ (0.87 versus $0.65 \mathrm{~kg} / \mathrm{m}^{3}$ ). As shown in Table 3 , the XAD16 productivity doubled with the adoption of the long column. As for IRA958 $\mathrm{Cl}$, in test IRA1 $(1.8 \mathrm{~m}, 2.8 \mathrm{~m} / \mathrm{h})$, this parameter was $70 \%$ lower than in XAD2 $(1.8 \mathrm{~m}, 3.1 \mathrm{~m} / \mathrm{h})$, despite the similar operating conditions. Comparing IRA2 $(1.8 \mathrm{~m}, 1.3 \mathrm{~m} / \mathrm{h})$ with IRA1 $(1.8 \mathrm{~m}, 2.8 \mathrm{~m} / \mathrm{h})$, the halving of the superficial velocity led on the one hand to a further $60 \%$ decrease in productivity but on the other hand to a 3 -fold increase in resin utilization efficiency.

\section{Conclusions}

In relation to the three goals stated in the Introduction, the following conclusions can be drawn.

(1) Both tested ion exchange resins (IRA67 and IRA958 $\mathrm{Cl}$ ) performed worse than nonionic XAD16 in terms of both $\mathrm{PC} / \mathrm{COD}$ selectivity and resin utilization efficiency.

(2) The addition to the OMW of a relevant amount of VFAs did not hinder PC adsorption on either resin, suggesting a noncompetitive adsorption mechanism. The $\mathrm{pH}$ increase from the natural value of the tested OMW (4.9) to neutrality did not impact PC adsorption on XAD16, favoured sorption on IRA958 Cl (quaternary ammonium functional group), and had a negative effect on IRA67 (tertiary amine functionalized).

(3) In the XAD16 breakthrough test, the increase in column length from $0.5 \mathrm{~m}$ to $1.8 \mathrm{~m}$ led to a marked improvement of the process performances in terms of resin utilization efficiency, resin productivity, PC adsorption yield, and $\mathrm{PC} / \mathrm{COD}$ enrichment factor. The process model, based on the assumption of nonequilibrium adsorption and characterized by overall mass-transfer resistance, proved capable of accurately interpreting the experimental curves in both the $0.5 \mathrm{~m}$ and $1.8 \mathrm{~m}$ columns.

Overall, the continuous flow PC adsorption/desorption process proved to be a promising one for OMW valorisation. Further research is required to evaluate the number of adsorption/desorption cycles that can be operated with the same resin load, to optimize PC desorption, and to perform economic optimization of the process.

\section{Abbreviations \\ OMW: Olive mill wastewater \\ PC: Phenolic compound \\ VFA: Volatile fatty acid.}

\section{Nomenclature}

\begin{tabular}{|c|c|}
\hline$A_{S}:$ & $\begin{array}{l}\text { Asymmetry factor, defined as ratio } \\
\text { between the leading and tailing semiwidth } \\
\text { of the peak at } 10 \% \text { of the peak height }(-)\end{array}$ \\
\hline$C_{L, i}:$ & $\begin{array}{l}\text { Liquid phase concentration of compound } i \\
(\mathrm{mg} / \mathrm{L})\end{array}$ \\
\hline$C_{L, \mathrm{PC}, 0}, C_{L, \mathrm{PC}, \mathrm{eq}}:$ & $\begin{array}{l}\text { Initial and final (equilibrium) PC } \\
\text { concentration in the liquid phase }(\mathrm{OMW}) \\
\text { during the isotherm tests }\left(\mathrm{mg}_{\mathrm{PC}} / \mathrm{L}\right)\end{array}$ \\
\hline$C_{S, i}:$ & $\begin{array}{l}\text { Solid phase (resin) concentration of } \\
\text { compound } i\left(\mathrm{mg} / \mathrm{g}_{\text {dry resin }}\right)\end{array}$ \\
\hline$C_{S, P C, \text { eq }}:$ & $\begin{array}{l}\text { Final (equilibrium) PC concentration in } \\
\text { the solid phase (resin) during the isotherm } \\
\text { tests } \\
\left(=\left(C_{L, \mathrm{PC}, 0} \cdot V_{L, \text { added }}-C_{L, \mathrm{PC}, \mathrm{eq}} \cdot V_{L, \text { final }}\right) / m_{S}\right) \\
\left(\mathrm{mg}_{\mathrm{PC}} / \mathrm{g}_{\text {dry resin }}\right)\end{array}$ \\
\hline$D_{\text {eq }}:$ & $\begin{array}{l}\text { Equivalent diffusion coefficient } \\
\left(=\alpha_{L} \cdot v_{\text {int }}\right)\left(\mathrm{m}^{2} / \mathrm{s}\right)\end{array}$ \\
\hline$d_{p}:$ & Average size of the packing particles (m) \\
\hline HETP: & $\begin{array}{l}\text { Height equivalent to a theoretical plate, in } \\
\text { the packed column }(\mathrm{m})\end{array}$ \\
\hline
\end{tabular}




\begin{tabular}{|c|c|}
\hline $\mathrm{HETP} / d_{p}:$ & $\begin{array}{l}\text { Reduced height equivalent to a theoretical } \\
\text { plate, in the packed column }(-)\end{array}$ \\
\hline$K_{\mathrm{eq}, i}:$ & $\begin{array}{l}\text { Adsorption constant of compound } \\
i \text {, defined as the slope of the linear } \\
\text { portion of the isotherm }\left(=C_{S, i, \mathrm{eq}} / C_{L, i, \mathrm{eq}}\right) \\
\left(\mathrm{L}_{\text {pore volume }} / \mathrm{kg}_{\text {dry resin }}\right)\end{array}$ \\
\hline$k_{L} a:$ & $\begin{array}{l}\text { Mass-transfer coefficient referred to liquid } \\
\text { volume }(1 / \mathrm{s})\end{array}$ \\
\hline$m_{i, \mathrm{fed}}:$ & $\begin{array}{l}\text { Mass of compound } i \text { fed to the column until } \\
\text { the breakpoint (mg) }\end{array}$ \\
\hline$m_{i, \text { sorbed }, 20 \%}:$ & $\begin{array}{l}\text { Mass of compound } i \text { adsorbed by the resin } \\
\text { at the breakpoint ( } \mathrm{mg} \text { ) }\end{array}$ \\
\hline$m_{S}:$ & $\begin{array}{l}\text { Mass of dry resin in the isotherm studies } \\
\left(g_{\text {dry resin }}\right)\end{array}$ \\
\hline$N:$ & $\begin{array}{l}\text { Number of theoretical plates in the column } \\
\text { packing }(-)\end{array}$ \\
\hline Q: & $\begin{array}{l}\text { Volumetric flow rate through the column } \\
\left(\mathrm{m}^{3} / \mathrm{s}\right)\end{array}$ \\
\hline$V_{i}$ : & $\begin{array}{l}\text { Adsorption column volume occupied by } \\
\text { component } i \text { (resin or sand) }\left(\mathrm{m}^{3}\right)\end{array}$ \\
\hline$V_{L, \text { added }}, V_{L, \text { final }}:$ & $\begin{array}{l}\text { OMW volume added to the solid and final } \\
\text { liquid volume resulting from the sum of } \\
\text { the added OMWs and of the water initially } \\
\text { contained in the activated resin in the } \\
\text { isotherm tests (L) }\end{array}$ \\
\hline$v_{\text {int }}:$ & Interstitial velocity $(\mathrm{m} / \mathrm{s})$ \\
\hline$v_{\text {sup }}:$ & $\begin{array}{l}\text { Superficial velocity, calculated as } \\
\text { (Q/column section) and equal to } v_{\text {int }} \cdot \varepsilon \\
(\mathrm{m} / \mathrm{s})\end{array}$ \\
\hline$Y_{\mathrm{ads}, i}:$ & $\begin{array}{l}\text { Adsorption yield of compound } i \text {, calculated } \\
\text { as } m_{i, \text { sorbed }} / m_{i, \text { initial }} \text { in the batch tests and as } \\
m_{i, \text { sorbed,20\% }} / m_{i, \text { fed,20\% }} \text { in the breakthrough } \\
\text { tests }(-)\end{array}$ \\
\hline$Y_{\mathrm{des}, i}:$ & $\begin{array}{l}\text { Desorption yield of compound } i \\
\text { in a breakthrough test, defined as } \\
m_{\mathrm{PC} \text {,desorbed }} / m_{\mathrm{PC} \text {,sorbed }}(-)\end{array}$ \\
\hline$\alpha_{L}:$ & Longitudinal dispersivity $(\mathrm{m})$ \\
\hline$\varepsilon_{i}:$ & $\begin{array}{l}\text { Effective porosity of component } i \text { (resin or } \\
\text { sand) }(-)\end{array}$ \\
\hline$\eta_{\text {resin }}:$ & $\begin{array}{l}\text { Resin utilization efficiency }\left(=m_{\mathrm{PC} \text {,sorbed,20\% }} /\right. \\
\left.m_{\mathrm{PC} \text {,sorbed,sat }}\right)(-)\end{array}$ \\
\hline$b^{\prime}$ & Resin bulk density (kg/L). \\
\hline
\end{tabular}

\section{Data Access}

The dataset underlying this paper has been published in the AMS Acta Institutional Research Repository (https://amsacta .unibo.it/) [66].

\section{Competing Interests}

The authors declare that they have no competing interests regarding the publication of this paper.

\section{Acknowledgments}

Project cofunding by the European Commission under Grant Agreements nos. 311933 (Water4Crops project, 7th FP) and
688320 (MADFORWATER project, H2020) is acknowledged. The authors wish to thank Lucio Donati and Alberto Filetti for their support in the experimental work. Ankita Kaushik acknowledges the Department of Biotechnology, Ministry of Science and Technology, Government of India, for supporting the exchange visit under project Grant BT/IN/EU/ 06SPW/2012.

\section{References}

[1] S. Dermeche, M. Nadour, C. Larroche, F. Moulti-Mati, and P. Michaud, "Olive mill wastes: biochemical characterizations and valorization strategies," Process Biochemistry, vol. 48, no. 10, pp. 1532-1552, 2013.

[2] L. C. Davies, A. M. Vilhena, J. M. Novais, and S. Martins-Dias, "Olive mill wastewater characteristics: modelling and statistical analysis," Grasas y Aceites, vol. 55, no. 3, pp. 233-241, 2004.

[3] L. Bertin, F. Ferri, A. Scoma, L. Marchetti, and F. Fava, "Recovery of high added value natural polyphenols from actual olive mill wastewater through solid phase extraction," Chemical Engineering Journal, vol. 171, no. 3, pp. 1287-1293, 2011.

[4] T. Yangui, S. Sayadi, A. Gargoubi, and A. Dhouib, "Fungicidal effect of hydroxytyrosol-rich preparations from olive mill wastewater against Verticillium dahliae," Crop Protection, vol. 29, no. 10, pp. 1208-1213, 2010.

[5] N. Rahmanian, S. M. Jafari, and C. M. Galanakis, "Recovery and removal of phenolic compounds from olive mill wastewater," Journal of the American Oil Chemists' Society, vol. 91, no. 1, pp. 1-18, 2014.

[6] G. Pekin, S. Haskök, S. Sargin et al., "Anaerobic digestion of Aegean olive mill effluents with and without pretreatment," Journal of Chemical Technology and Biotechnology, vol. 85, pp. 976-982, 2010

[7] K. L. Tuck and P. J. Hayball, "Major phenolic compounds in olive oil: metabolism and health effects," Journal of Nutritional Biochemistry, vol. 13, no. 11, pp. 636-644, 2002.

[8] A. El-Abbassi, H. Kiai, and A. Hafidi, "Phenolic profile and antioxidant activities of olive mill wastewater," Food Chemistry, vol. 132, no. 1, pp. 406-412, 2012.

[9] N. Kalogerakis, M. Politi, S. Foteinis, E. Chatzisymeon, and D. Mantzavinos, "Recovery of antioxidants from olive mill wastewaters: a viable solution that promotes their overall sustainable management," Journal of Environmental Management, vol. 128, pp. 749-758, 2013.

[10] C. Fortes, J. A. García-Vilas, A. R. Quesada, and M. Á. Medina, "Evaluation of the anti-angiogenic potential of hydroxytyrosol and tyrosol, two bio-active phenolic compounds of extra virgin olive oil, in endothelial cell cultures," Food Chemistry, vol. 134, no. 1, pp. 134-140, 2012.

[11] F. Puoci, A. Scoma, G. Cirillo, L. Bertin, F. Fava, and N. Picci, "Selective extraction and purification of gallic acid from actual site olive mill wastewaters by means of molecularly imprinted microparticles," Chemical Engineering Journal, vol. 198-199, pp. 529-535, 2012.

[12] P. S. Rodis, V. T. Karathanos, and A. Mantzavinou, "Partitioning of olive oil antioxidants between oil and water phases," Journal of Agricultural and Food Chemistry, vol. 50, no. 3, pp. 596-601, 2002.

[13] T.-I. Lafka, A. E. Lazou, V. J. Sinanoglou, and E. S. Lazos, "Phenolic and antioxidant potential of olive oil mill wastes," Food Chemistry, vol. 125, no. 1, pp. 92-98, 2011. 
[14] A. De Leonardis, V. Macciola, G. Lembo, A. Aretini, and A. Nag, "Studies on oxidative stabilisation of lard by natural antioxidants recovered from olive-oil mill wastewater," Food Chemistry, vol. 100, no. 3, pp. 998-1004, 2007.

[15] C. M. Galanakis, E. Tornbergb, and V. Gekasc, "Recovery and preservation of phenols from olive waste in ethanolic extracts," Journal of Chemical Technology and Biotechnology, vol. 85, no. 8, pp. 1148-1155, 2010.

[16] T. J. Klen and B. M. Vodopivec, "Ultrasonic extraction of phenols from olive mill wastewater: comparison with conventional methods," Journal of Agricultural and Food Chemistry, vol. 59, no. 24, pp. 12725-12731, 2011.

[17] A. El-Abbassi, H. Kiai, J. Raiti, and A. Hafidi, "Application of ultrafiltration for olive processing wastewaters treatment," Journal of Cleaner Production, vol. 65, pp. 432-438, 2014.

[18] D. P. Zagklis, A. I. Vavouraki, M. E. Kornaros, and C. A. Paraskeva, "Purification of olive mill wastewater phenols through membrane filtration and resin adsorption/desorption," Journal of Hazardous Materials, vol. 285, pp. 69-76, 2015.

[19] E. Garcia-Castello, A. Cassano, A. Criscuoli, C. Conidi, and E. Drioli, "Recovery and concentration of polyphenols from olive mill wastewaters by integrated membrane system," Water Research, vol. 44, no. 13, pp. 3883-3892, 2010.

[20] C. Conidi, R. Mazzei, A. Cassano, and L. Giorno, "Integrated membrane system for the production of phytotherapics from olive mill wastewaters," Journal of Membrane Science, vol. 454, pp. 322-329, 2014.

[21] A. El-Abbassi, H. Kiai, J. Raiti, and A. Hafidi, "Cloud point extraction of phenolic compounds from pretreated olive mill wastewater," Journal of Environmental Chemical Engineering, vol. 2, no. 3, pp. 1480-1486, 2014.

[22] O. Gortzi, S. Lalas, A. Chatzilazarou, E. Katsoyannos, S. Papaconstandinou, and E. Dourtoglou, "Recovery of natural antioxidants from olive mill wastewater using Genapol-X080," Journal of the American Oil Chemists' Society, vol. 85, no. 2, pp. 133-140, 2008.

[23] C. M. Galanakis, "Emerging technologies for the production of nutraceuticals from agricultural by-products: a viewpoint of opportunities and challenges," Food and Bioproducts Processing, vol. 91, no. 4, pp. 575-579, 2013.

[24] M. L. Soto, A. Moure, H. Domínguez, and J. C. Parajó, "Recovery, concentration and purification of phenolic compounds by adsorption: a review," Journal of Food Engineering, vol. 105, no. 1, pp. 1-27, 2011.

[25] J. Kammerer, R. Carle, and D. R. Kammerer, "Adsorption and ion exchange: basic principles and their application in food processing," Journal of Agricultural and Food Chemistry, vol. 59, no. 1, pp. 22-42, 2011.

[26] L. Bertin, D. Frascari, H. Domínguez, E. Falqué, F. A. Riera Rodriguez, and S. Alvarez Blanco, "Conventional purification and isolation," in Food Waste Recovery: Processing Technologies and Techniques, C. M. Galanakis, Ed., pp. 149-172, Elsevier/Academic Press, London, UK, 2015.

[27] M. Caetano, C. Valderrama, A. Farran, and J. L. Cortina, "Phenol removal from aqueous solution by adsorption and ion exchange mechanisms onto polymeric resins," Journal of Colloid and Interface Science, vol. 338, no. 2, pp. 402-409, 2009.

[28] L. Zhu, Y. Deng, J. Zhang, and J. Chen, "Adsorption of phenol from water by $\mathrm{N}$-butylimidazolium functionalized strongly basic anion exchange resin," Journal of Colloid and Interface Science, vol. 364, no. 2, pp. 462-468, 2011.
[29] Y. Ku and K.-C. Lee, "Removal of phenols from aqueous solution by XAD-4 resin," Journal of Hazardous Materials, vol. 80, no. 1-3, pp. 59-68, 2000.

[30] Y. Ku, K.-C. Lee, and W. Wang, "Removal of phenols from aqueous solutions by purolite A-510 Resin," Separation Science and Technology, vol. 39, no. 4, pp. 911-923, 2004.

[31] M. Carmona, A. D. Lucas, J. L. Valverde, B. Velasco, and J. F. Rodríguez, "Combined adsorption and ion exchange equilibrium of phenol on Amberlite IRA-420," Chemical Engineering Journal, vol. 117, no. 2, pp. 155-160, 2006.

[32] C. H. Geerkens, A. E. Matejka, R. M. Schweiggert, D. R. Kammerer, and R. Carle, "Optimization of polyphenol recovery from mango peel extracts by assessing food-grade adsorbent and ion exchange resins and adsorption parameters using a Doptimal design," European Food Research and Technology, vol. 241, no. 5, pp. 627-636, 2015.

[33] J. G. Streeter, "Simple partial purification of D-pinitol from soybean leaves," Crop Science, vol. 41, no. 6, pp. 1985-1987, 2001.

[34] A. Di Mauro, B. Fallico, A. Passerini, P. Rapisarda, and E. Maccarone, "Recovery of hesperidin from orange peel by concentration of extracts on styrene-divinylbenzene resin," Journal of Agricultural and Food Chemistry, vol. 47, no. 10, pp. 4391-4397, 1999.

[35] Y. Fu, Y. Zu, W. Liu et al., "Optimization of luteolin separation from pigeonpea [Cajanus cajan (L.) Millsp.] leaves by macroporous resins," Journal of Chromatography A, vol. 1137, no. 2, pp. 145-152, 2006.

[36] A. Schieber, P. Hilt, H.-U. Endreß, C. Rentschler, and R. Carle, "A new process for the combined recovery of pectin and phenolic compounds from apple pomace," Innovative Food Science and Emerging Technologies, vol. 4, no. 1, pp. 99-107, 2003.

[37] J. Kammerer, D. R. Kammerer, U. Jensen, and R. Carle, "Interaction of apple polyphenols in a multi-compound system upon adsorption onto a food-grade resin," Journal of Food Engineering, vol. 96, no. 4, pp. 544-554, 2010.

[38] J. Kammerer, D. R. Kammerer, and R. Carle, "Impact of saccharides and amino acids on the interaction of apple polyphenols with ion exchange and adsorbent resins," Journal of Food Engineering, vol. 98, no. 2, pp. 230-239, 2010.

[39] A. Agalias, P. Magiatis, A.-L. Skaltsounis et al., "A new process for the management of olive oil mill waste water and recovery of natural antioxidants," Journal of Agricultural and Food Chemistry, vol. 55, no. 7, pp. 2671-2676, 2007.

[40] D. R. Kammerer, R. Carle, R. A. Stanley, and Z. S. Saleh, "Pilotscale resin adsorption as a means to recover and fractionate apple polyphenols," Journal of Agricultural and Food Chemistry, vol. 58, no. 11, pp. 6787-6796, 2010.

[41] T. J. Buran, A. K. Sandhu, Z. Li, C. R. Rock, W. W. Yang, and L. Gu, "Adsorption/desorption characteristics and separation of anthocyanins and polyphenols from blueberries using macroporous adsorbent resins," Journal of Food Engineering, vol. 128, pp. 167-173, 2014.

[42] M. Otero, M. Zabkova, and A. E. Rodrigues, "Phenolic wastewaters purification by thermal parametric pumping: modeling and pilot-scale experiments," Water Research, vol. 39, no. 15, pp. 3467-3478, 2005.

[43] J. Kim, M. Yoon, H. Yang et al., "Enrichment and purification of marine polyphenol phlorotannins using macroporous adsorption resins," Food Chemistry, vol. 162, pp. 135-142, 2014.

[44] K. Chen, H. Lyu, S. Hao, G. Luo, S. Zhang, and J. Chen, "Separation of phenolic compounds with modified adsorption resin 
from aqueous phase products of hydrothermal liquefaction of rice straw," Bioresource Technology, vol. 182, pp. 160-168, 2015.

[45] Y. Liu, Q. Bai, Y. Liu et al., "Simultaneous purification of tea polyphenols and caffeine from discarded green tea by macroporous adsorption resins," European Food Research and Technology, vol. 238, no. 1, pp. 59-69, 2014.

[46] M. D. Víctor-Ortega, J. M. Ochando-Pulido, D. AiradoRodríguez, and A. Martínez-Ferez, "Comparison between different ion exchange resins combinations for final treatment of olive mill effluent," Separation and Purification Technology, vol. 158, pp. 374-382, 2016.

[47] D. Frascari, A. E. M. Bacca, F. Zama, L. Bertin, F. Fava, and D. Pinelli, "Olive mill wastewater valorisation through phenolic compounds adsorption in a continuous flow column," Chemical Engineering Journal, vol. 283, pp. 293-303, 2016.

[48] F. Ferri, L. Bertin, A. Scoma, L. Marchetti, and F. Fava, "Recovery of low molecular weight phenols through solidphase extraction," Chemical Engineering Journal, vol. 166, no. 3 , pp. 994-1001, 2011.

[49] A. Scoma, C. Pintucci, L. Bertin, P. Carlozzi, and F. Fava, "Increasing the large scale feasibility of a solid phase extraction procedure for the recovery of natural antioxidants from olive mill wastewaters," Chemical Engineering Journal, vol. 198-199, pp. 103-109, 2012.

[50] M. T. Agler, B. A. Wrenn, S. H. Zinder, and L. T. Angenent, "Waste to bioproduct conversion with undefined mixed cultures: the carboxylate platform," Trends in Biotechnology, vol. 29, no. 2, pp. 70-78, 2011.

[51] G. A. Martinez, S. Rebecchi, D. Decorti et al., "Towards multi-purpose biorefinery platforms for the valorisation of red grape pomace: production of polyphenols, volatile fatty acids, polyhydroxyalkanoates and biogas," Green Chemistry, vol. 18, no. 1, pp. 261-270, 2015.

[52] S. Campanari, F. A. E Silva, L. Bertin, M. Villano, and M. Majone, "Effect of the organic loading rate on the production of polyhydroxyalkanoates in a multi-stage process aimed at the valorization of olive oil mill wastewater," International Journal of Biological Macromolecules, vol. 71, pp. 34-41, 2014.

[53] GE Healthcare Bio-Sciences AB, Column efficiency testingapplication note 28-9372-07 AA, Uppsala, Sweden, 2010, https:// www.gelifesciences.com/gehcls_images/GELS/Related\%20Content/Files/1352880951136/litdoc28937207_20141127221416.pdf.

[54] P. Englezos and N. Kalogerakis, Applied Parameter Estimation for Chemical Engineers, Marcel Dekker, New York, NY, USA, 2001.

[55] F. Zama, R. Ciavarelli, D. Frascari, and D. Pinelli, "Numerical parameters estimation in models of pollutant transport with chemical reaction," in System Modeling and Optimization: 25th IFIP TC 7 Conference, CSMO 2011, Berlin, Germany, September 12-16, 2011, Revised Selected Papers, vol. 391 of IFIP Advances in Information and Communication Technology, pp. 547-556, Springer, Heidelberg, Germany, 2013.

[56] W. L. McCabe, J. C. Smith, and P. Harriott, Unit Operations of Chemical Engineering, McGraw-Hill, New York, NY, USA, 6th edition, 2001.

[57] D. Frascari, G. Zanaroli, G. Bucchi et al., "Trichloroethylene aerobic cometabolism by suspended and immobilized butanegrowing microbial consortia: a kinetic study," Bioresource Technology, vol. 144, pp. 529-538, 2013.

[58] M. Monti, A. Scoma, G. A. Martinez, L. Bertin, and F. Fava, "Uncoupled hydrogen and volatile fatty acids generation in a two-step biotechnological anaerobic process fed with actual site wastewater," New Biotechnology, vol. 32, no. 3, pp. 341-346, 2015.

[59] J. Kammerer, C. Schweizer, R. Carle, and D. R. Kammerer, "Recovery and fractionation of major apple and grape polyphenols from model solutions and crude plant extracts using ion exchange and adsorbent resins," International Journal of Food Science and Technology, vol. 46, no. 8, pp. 1755-1767, 2011.

[60] C. M. Galanakis, "Separation of functional macromolecules and micromolecules: from ultrafiltration to the border of nanofiltration," Trends in Food Science and Technology, vol. 42, no. 1, pp. 44-63, 2015.

[61] C. M. Galanakis, E. Tornberg, and V. Gekas, "Clarification of high-added value products from olive mill wastewater," Journal of Food Engineering, vol. 99, no. 2, pp. 190-197, 2010.

[62] I. D’Antuono, V. G. Kontogianni, K. Kotsiou et al., "Polyphenolic characterization of olive mill wastewaters, coming from Italian and Greek olive cultivars, after membrane technology," Food Research International, vol. 65, pp. 301-310, 2014.

[63] C. Russo, "A new membrane process for the selective fractionation and total recovery of polyphenols, water and organic substances from vegetation waters (VW)," Journal of Membrane Science, vol. 288, no. 1-2, pp. 239-246, 2007.

[64] P. Xiao, P. F.-X. Corvini, Y. Dudal, and P. Shahgaldian, "Design and high-throughput synthesis of cyclodextrin-based polyurethanes with enhanced molecular recognition properties," Polymer Chemistry, vol. 4, no. 4, pp. 942-946, 2013.

[65] P. Xiao, P. Corvini, Y. Dudal, and P. Shahgaldian, "Design of cyclodextrin-based photopolymers with enhanced molecular recognition properties: a template-free high-throughput approach," Macromolecules, vol. 45, no. 14, pp. 5692-5697, 2012.

[66] D. Pinelli, D. Frascari, and L. Bertin, "MADFORWATERWP2: adaptation of wastewater treatment technologies for agricultural reuse-task 2.3: agro-industrial wastewater treatment-Subtask 2.3.1: treatment of olive mill wastewater-olive mill wastewater treatment by polyphenol separation and anaerobic digestion," AMS Acta Institutional Research Repository, 2016. 


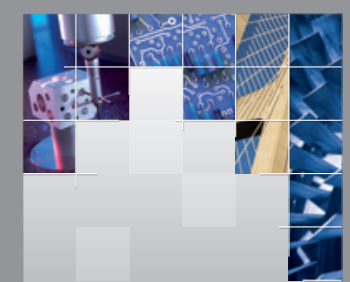

\section{Enfincering}
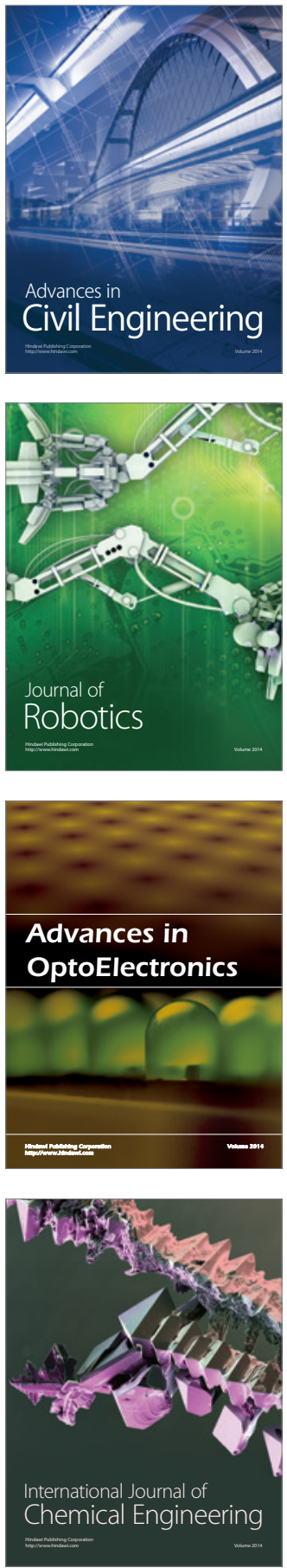

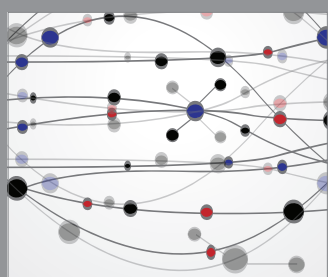

The Scientific World Journal

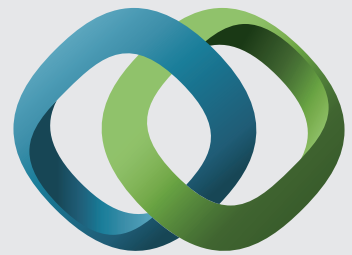

\section{Hindawi}

Submit your manuscripts at

http://www.hindawi.com
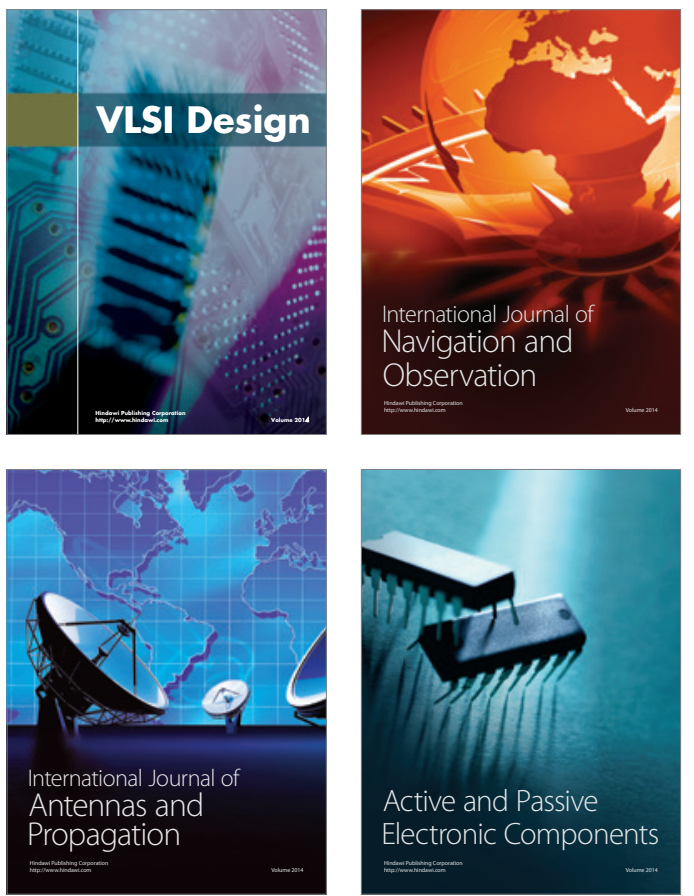
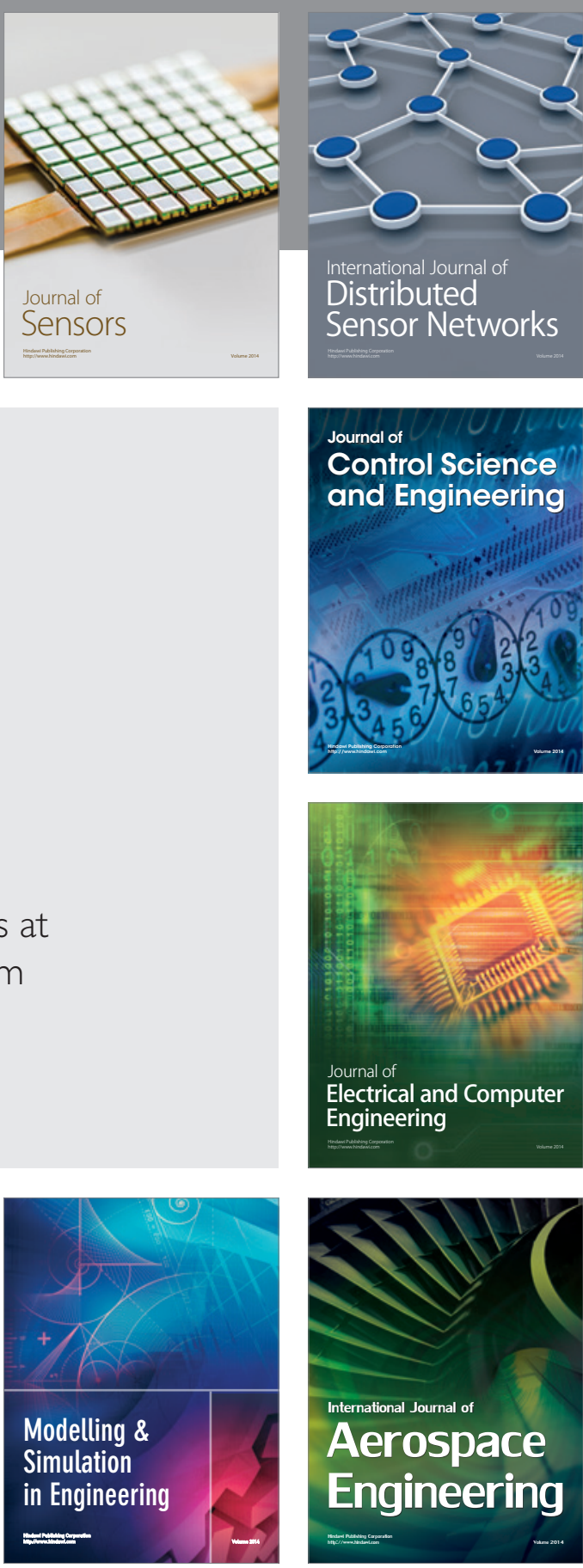

International Journal of

Distributed

Sensor Networks

Journal of

Control Science

and Engineering
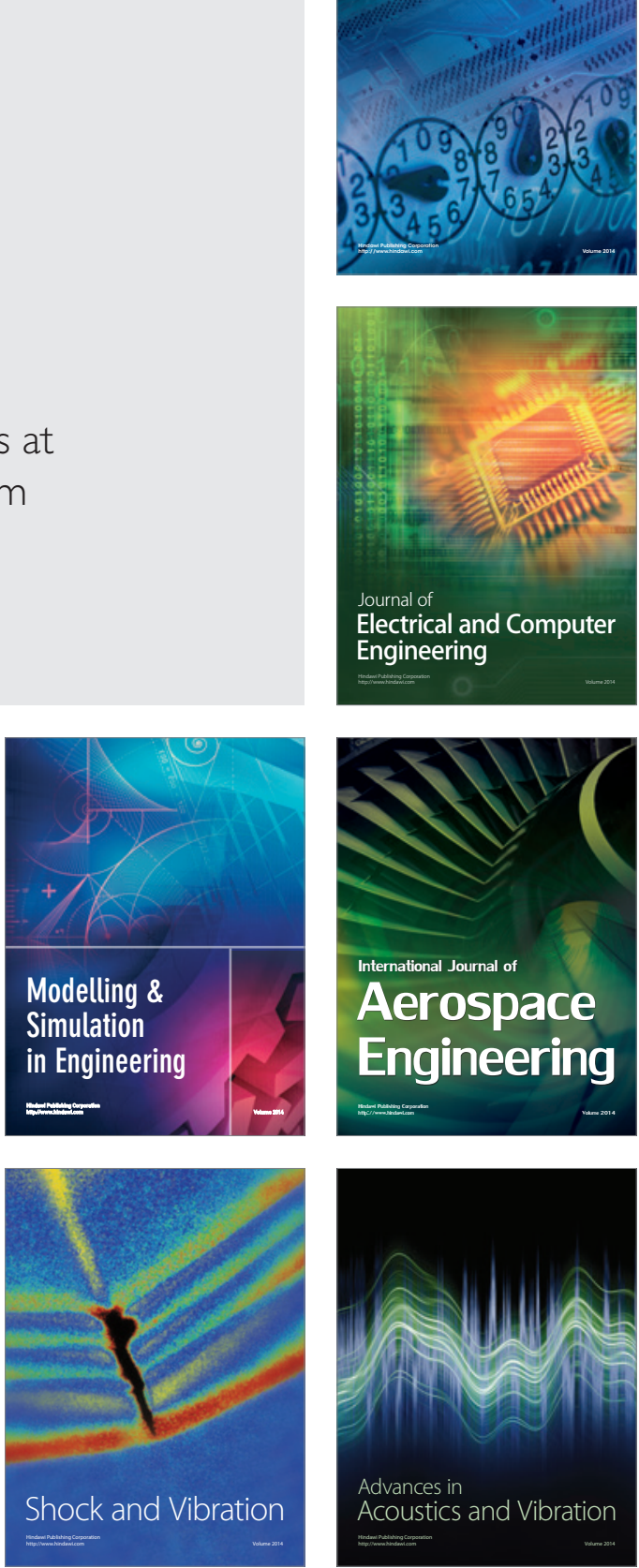